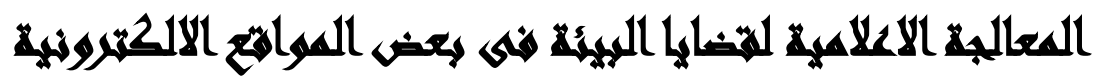

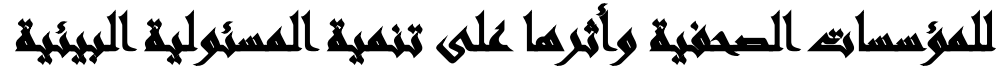

\section{لكي الجمهمور}

\section{[1 $\leqslant]$}

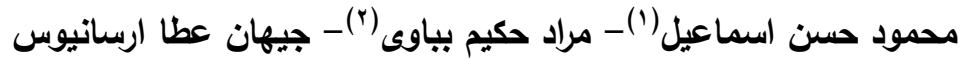

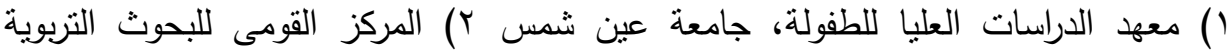

والتنمية

\section{varill}

تتاولت الدراسة موضوع المعالجة الإعلامية للقضايا البيئية فى بعض مواقع المؤسسات

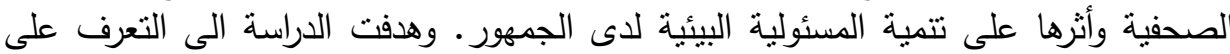

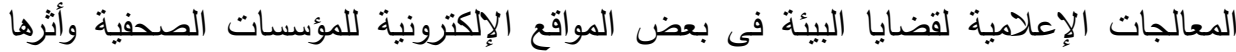

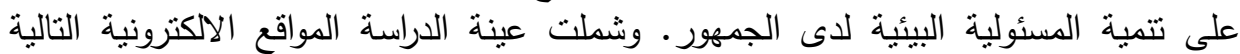

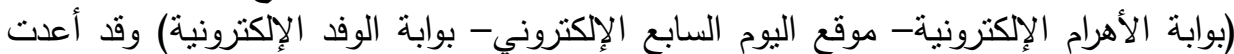

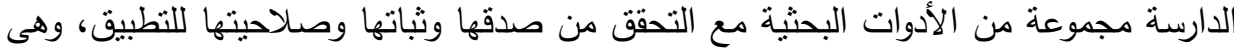

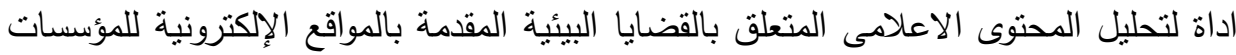

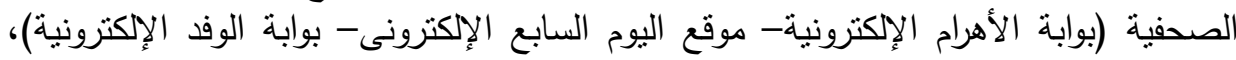
واستمارة استبيان لإستطلاع آراء واهتمامات الجمهور فيما تقدمه المواقع الإلكترونية فيما يتعلق الإنق بالقضايا البيئية، كما أعدت مقياس المسئولية البيئية لقياس أثر المعالجة الإعلامية للقضايا

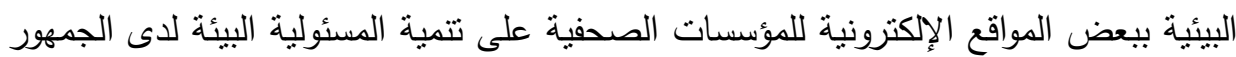

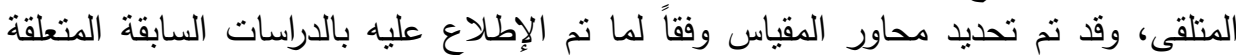

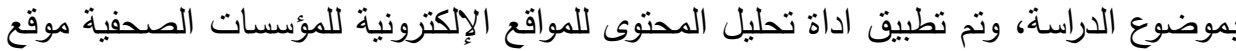

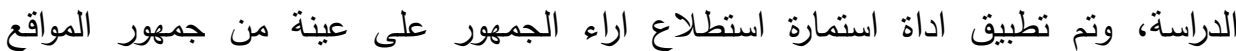

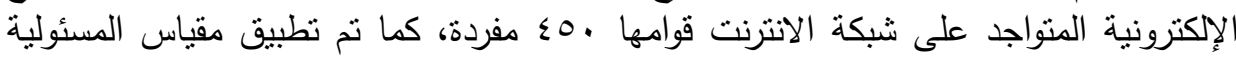

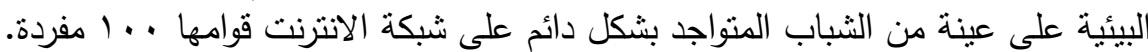

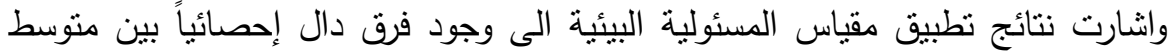

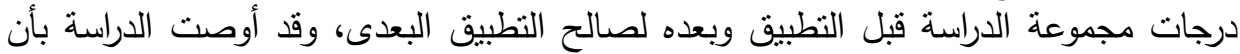

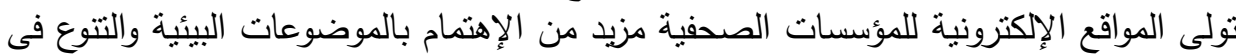
إستخدام القوالب المختلفة فى عرض القضايا البيئية وكذلك عرض كافة الافية جوانب القضية البيئية

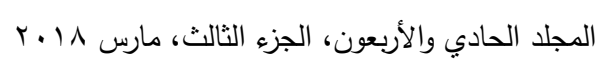




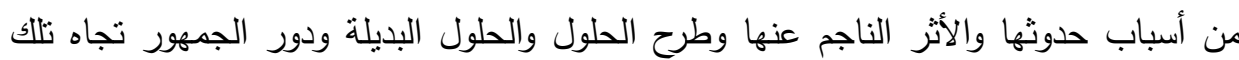
القضايا وكيفية المشاركة فى حلها من خلال سلوك بيئى إيجابى أوالمشاركة فى اتخاذ القرال القرار

الكلمات الدالة: القضايا البيئية، المواقع الإككترونية، المؤسسات الصحفية، المسؤلية البيئية.

\section{xamadl}

أصبح الإعلام أكثر إنفتاحا بعد الثثرة التكنولوجية، حيث ظهرت المواقع والصحف الإكترونية وإتسع دائرة القراء وأصبحت تتخطى الحدود الجغرافية، ومن مميزات استخدام شبكة الإنترنت فى مجال الصحافة سرعة الإنتشار للصحف وايضا للمحتوى المقدم بها، والقدرة على

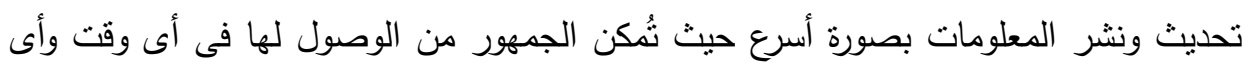

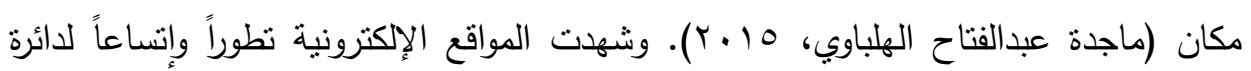
المطلعين بها بعد إنتشار الهواتف الذكية التى تتيح للقارئ الوصول للمواقع الإلكترونية المختلفة

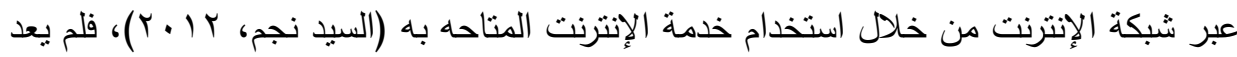
رواد المواقع الإلكترونية هم مستخدمى الكمبيوتز فقط وانما انسعت دائرة المطلعين لتتمل كافة الفئات والاعمار المختلفة نظراً لإنتشار استخدام تلك الهواتف بين كافة فئات المجتمع وفى لهى مختلف الأعمار، وقد أصبحت الصحافة المُقدمة عبر شبكة الإنترنت من خلال المواقع

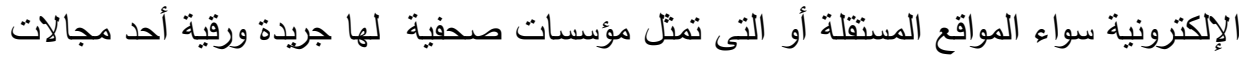
الإعلام البيئى الهامة، وتكمن أهمية المواقع الإلكترونية كإحدى مجالات الإعلام البيئى فى هـ

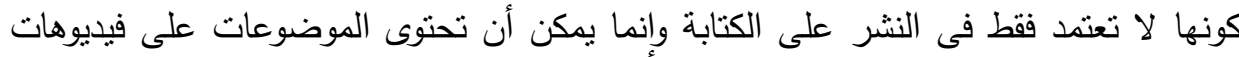
أوتسجيلات صوتيه أويتم بث الحدث مباشرةً على موقع الصحيفة الإكترونية اثثاء حدوثة

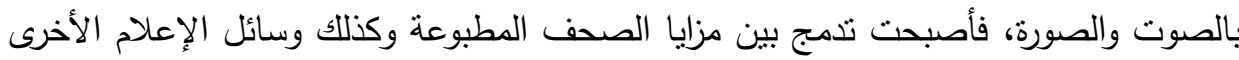

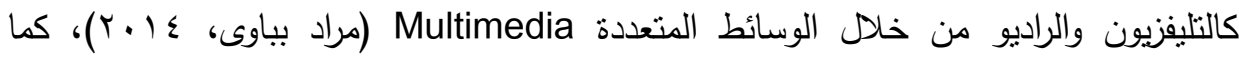
يمُكِنها عمل افلام وثائقية أو تسجيليه خاصة بحدث ما، فهى لديها كل ما للميديا من إمكانيات وما للصحف أيضا، فالإعلام الرقمى أو الصحافة الإلكترونية جمعت خصائص وسائه وسائل الإعلام

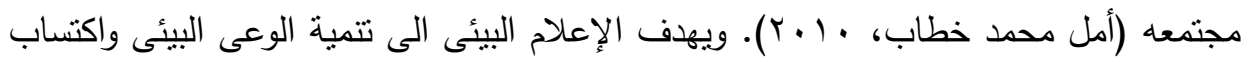

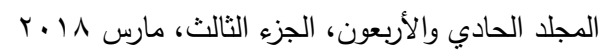


المعرفة والمهارات البيئية والسلوك الايجابى تجاه البيئة كذللك تتمية القيم والاتجاهات الإيجابية تجاه البيئة، كما نتعاظم أهمية الإعلام البيئي ودوره في الإنذار المبكر ورصد أي خلل بيئي يحدث، وتعريف الفرد ببيئته وتكامل أجزائها الإجتماعية والتقافية والطبيعية وقدرة الفرد على الإنى

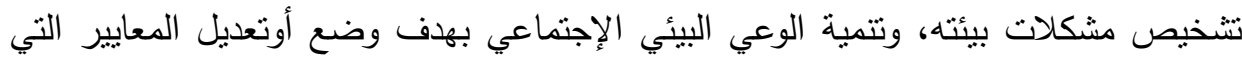
تعطي الفرد والجماعة إمكانية معرفة العوامل المخلة بالبيئة وأساليب وطرق مكافحتها، كما يعمل لهالئل على تتمية الوعي العام تجاه القضايا البيئية، وشعور الأفراد بمسئولية تجاه البيئة، وبالتالى بهدف لتحسين نوعية الحياة دون الإضرار بالموارد، ودون تعريض حياة الأجيال القادمة للخطر ، وأيضاً تتمية القدرات البيئية وحمايتها بما يتحقق معه تكييف وظيفي سليم إجتماعياً وحيوياً للمواطنين

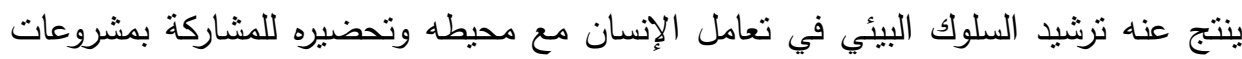
حماية البيئة والمحافظة على الموارد البيئية.

\section{مهرحلة التراسما}

من خلال الإطلاع على الدراسات السابقة فى موضوع الدراسة، قد اكدت الدراسات السابقة

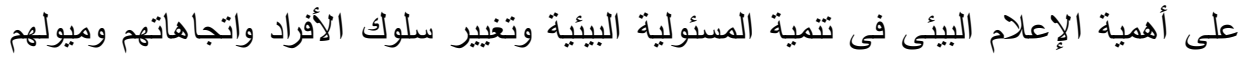

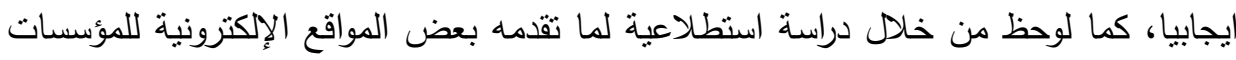

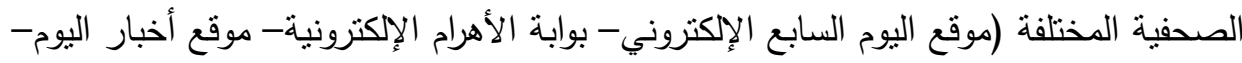
موقع الثروق - موقع المصرى اليوم- بوابة الوفد) فيما يتعلق بالقضايا البيئية، الآتى:

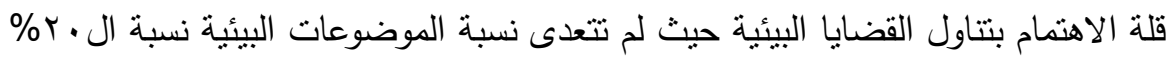

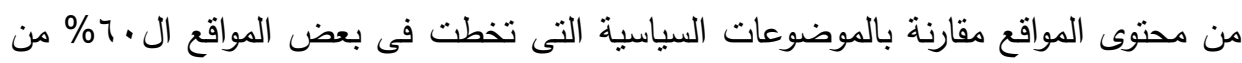

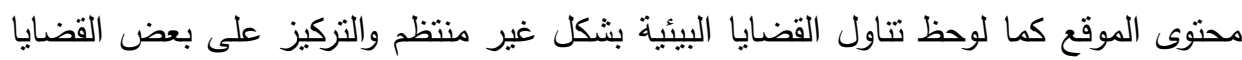

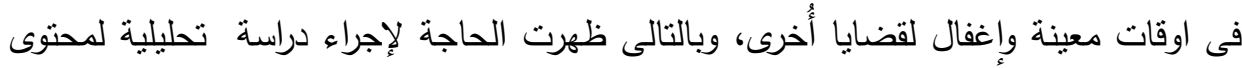
المواقع الإلكترونية للوقوف على مدى نتاول المواقع الإكترونية للمؤسسات الصحفية للقضايا

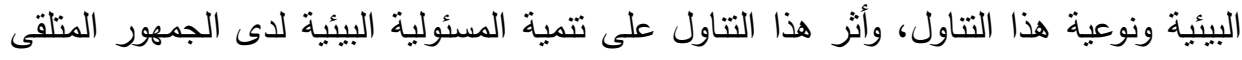
ومن هنا تتضح مشكلة الدراسة والتى تحددت فى السؤال الرئيس التالى: 
ما واقع المعالجات الإعلامية لقضايا البيئة فى بعض المواقع الإكترونية للمؤسسات الصحفية

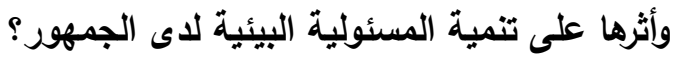
والذى انبتقت منه نساؤلات الدراسة التالية: أسئلة الدراسةة:

ا. ما أهم قضايا البيئة التى نتاولتها المواقع الإكترونية للمؤسسات الصحفية الثلاثة (بوابة

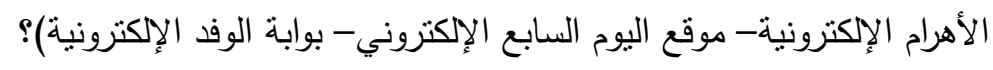

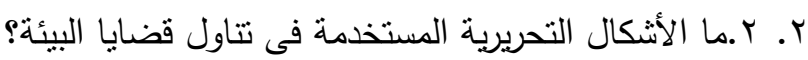

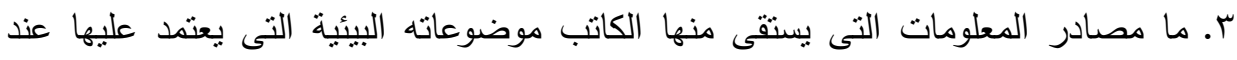
تتاول قضايا البيئة بالصحف الإككترونية؟ ع. ما اللغة التى تقدم من خلالها قضايا البيئة؟ 0. ما هى الوسائط التعبيرية المستخدمة (فيديو - الصور - الرسوم التخطيطية- نصوص فائقةكلمات نشطة- الاذاعة.... وغيرها)؟ هاتط الفيريه 7. ما أثر المعالجة الإعلامية للقضايا البيئية بالمواقع الإلكترونية الثلاثة (بوابة الأهرام الإكترونية- موقع البوم السابع الإلكتروني- بوابة الوفد الإلكترونية) فى تتمية المسئولية

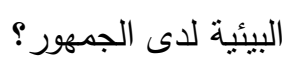

\section{أهمه التواسمة}

1 - تكتسب هذه الدراسة أهمية كبيرة من الناحية الموضوعية، ولاسيما في ضوء الإهتمام الرسمى

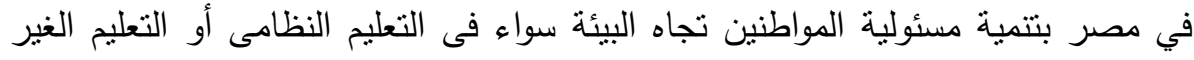
نظامى والمتمنل فى وسائل الإعلام المختلفة من بينها الصحف وكذلك المواقع الإكترونية

$$
\text { للمؤسسات الصحفية سواء قومية أو حزبية أو مستقلة. }
$$

r- تكمن أهمية هذه الدراسة فى كون الصحافة عبر شبكة الانترنت أصبحت أحد أهم وسائل الإعلام الأكثر والأسرع انتشاراً. 
r- خصائص إستخدام شبكة الإنترنت التى تتيح للأفراد الوصول للمواقع الإلكترونية فى أى وقت وأى مكان، كما ساهم إنتشار الهواتف الذكية التى نتيح الوصول لتلك المواقع الإكترونية فى ازدياد تلك الاهمية.

ع- الصحافة عبر الإنترنت أصبحت أحد الوسائل الاعلامية التى تعمل على تشكيل وعى افراد

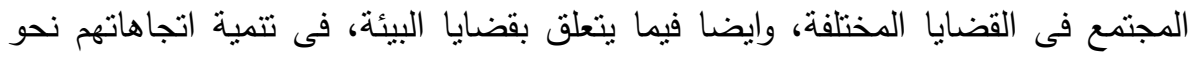
تللك القضايا وتوجيه سلوكهم وحثهم على المشاركة الايجابية وبالتالى تتمية المسئولية البيئية لايثهم. ه- الصحافة عبر شبكة الإنترنت متجاوزة الحدود الزمنية والمكانية ويمكن للفرد الإطلاع على ما تقدمه فى أى مكان فى العالم وفى أى وقت، طالما انه بمنلك إمكانية النفاذ عبر الإنترنت من خلال أجزة الكمبيوتر والتليفونات المحمولة الذكية. צ- الصحافة عبر الإنترنت تمكن الجمهور من الاختيار ما بين الصوت والصورة والنص

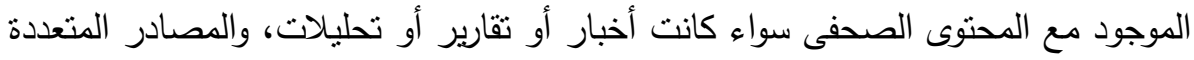
فالقارئ ليس أمامه قصة إخبارية واحده فقط حول القضية بل لديه كل القصص التى نشرت

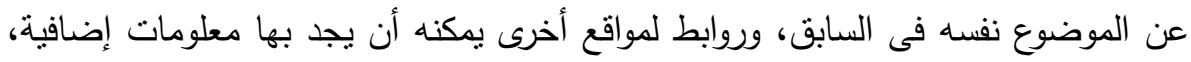

وبين يديه ايضا خدمات متعددة يمكنه الإختيار من بينها. يمكن أن يستقفيد بهذه الدراسة:

• الصحفيين المتخصصين فى مجال البيئة بالمواقع الإلكترونية للمؤسسات الصحفية بما ينبغي أن يقوموا به عند نتاول الموضوعات البيئية، نظرا لما ستتركه من نتائج.

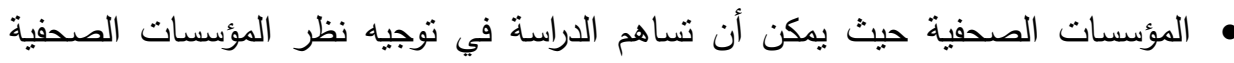
والكتاب والصحفيين والمحررين للوضع الحالى لقضايا البيئة التى تعالجها المواقع الالكترونية

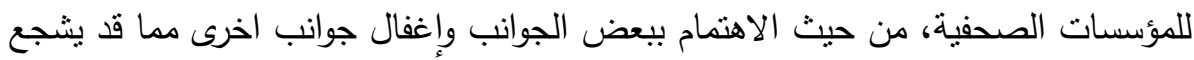
على القيام بدراسات أُخرى حول الإعلام البيئى بالمواقع الإلكترونية للمؤسسات الصحفية الصفية.

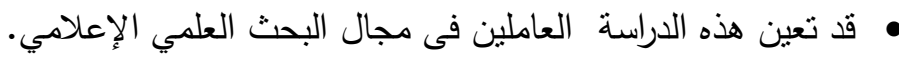
كما انها ستعود بالفائدة على الجمهور المطلع على المواقع الإِكترونية لما ستتركه من نتائج ايجابية على اداء الصحفيين المتخصصين فى مجال البيئة بنلك المواقع. 


\section{أهصاهيت التوراسة}

تهدف الدراسة الى التعرف على واقع المعالجة الإعلامية لقضايا البيئة فى بعض المواقع

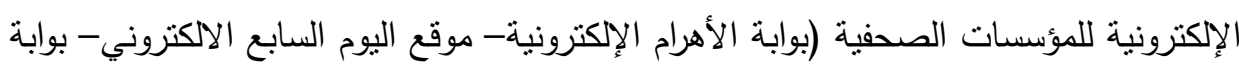
الوفد الإلكترونية).

وقياس أثز التتاول الإعلامى للقضايا البيئية بتلك المواقع الإلكترونية للمؤسسات الصحفية

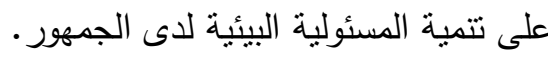

\section{مسوت وكميند السراسمة}

تقتصر الدراسة على بعض المواقع الإلكترونية للمؤسسات الصحفية وهى (بوابة الأهرام

$$
\text { الإلكترونية- موقع اليوم السابع الإلكترونى - بوابة الوفد الإكترونية). }
$$

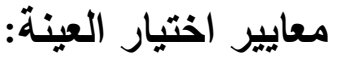

وقد نم إختيار هذه المواقع بناءً على دراسة إستطلاعية أوضحت نتائجها أن هذه المواقع من أكثر المواقع التى يتعرض لها الجمهور، كما تم إختيارها وفقاً للمعايير التالية: • بوابة الأهرام الإكترونية: لكونها تتبع مؤسسة الأهرام، وتهنم بالثشأن العام، وهي صهي صحيفة قومية واسعة الانتشار وهى تمنل مؤسسة صحفية قومية.

• موقع اليوم السابع الإلكترونى: يتبع مؤسسة اليوم السابع، وهيى مؤسسة صدئه صحفية مستقلة. • بوابة الوفد الإكترونية: تتبع حزب الوفد من المواقع الإلكترونية الحزبية الاكثر انتشارا، تمثل مونل مؤسسة صحفية حزبية وهى جريدة الوفد.

تم إجراء الدراسة وفقا للفترة الزمنية التى حددت وفيهاً للمعايير العلمية والاحصائية بما يحقق أهداف الدراسة حيث حددت الفترة الزمنية لتتاول المحتويات التى اثتنملت عليها المواقع

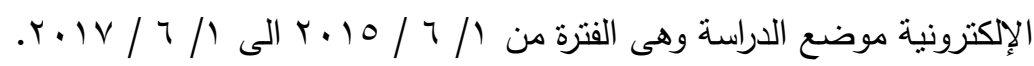




\section{منهمج السراسمة}

تستخدم الدراسة (المنهج الوصفى التحليلي)، لدراسة المعالجة الإعلامية لقضايا البيئة فى بعض المؤسسات الصحفية. وبالتالي تسعى هذه الدراسة لجمع المعلومات عن تتاول المواقع الإككترونية لبعض المؤسسات الصحفية للقضايا البيئية، حيث يرتبط مفهوم البحث الوصفي

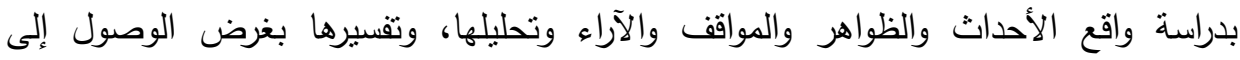
إسنتناجات مفيدة، إما لتصحيح هذا الواقع، أو تحديثه، أو استكماله، أو تطويره.

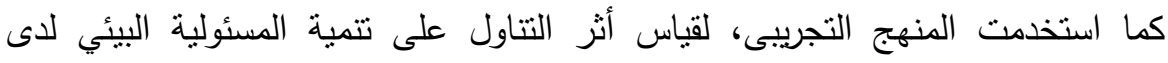
الجههور، المنهج التجريبي هو : "المنهج الذي يقوم في الأساس على دراسة الظواهر الإنسانية

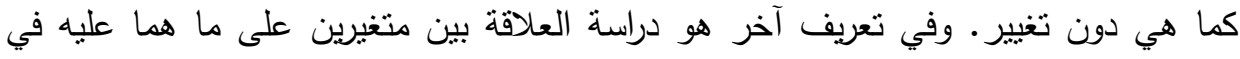
الواقع دون التحكم في المتغيرات".

الدنهج التجريبى فى الدراسات أو العلوم الإنسانية ينقسم البحث التجريبي في كيفية تتفيذه

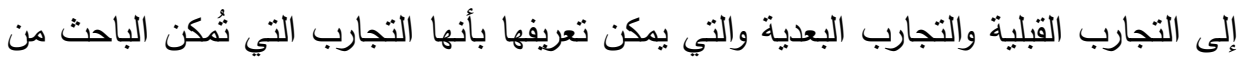

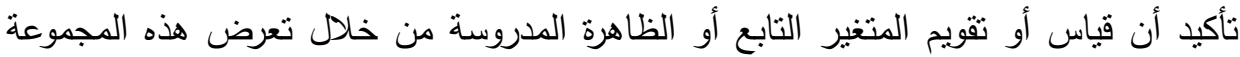

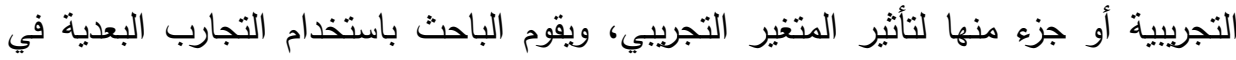
حالثنين: أولاً: في حالة منهج الوحدة الواحدة وهو القائم على دراسة مجموعة واحدة تحت تأثثر متغيرين مستقلين أو أكثر بأسلوب التتابع ودون الحاجة لاستخدام مجموعة ضابطة.

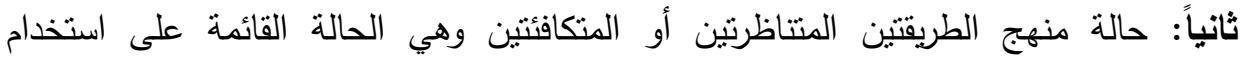
مجموعتين إحداهما تجريبية والأخرى ضابطة، ويتم من خلالها عرض المجموعة التجريبية للمتغيرات المستقلة أو السببية مراعاة في ذلك فصل تأثيره عن المجموعة الضابطة. وقد استخدمت الباحثة الأسلوب الاول من خلال استخدام التجارب البعدية القائم على لى لئه دراسة مجموعة واحدة تحت تأثثر متغيرين مستقلين أوأكثر بأسلوب التتابع دون الحاجة لإستخدام 


\section{أسوامت التوراسة}

1-قائمة بالقضايا والمشكلات البيئية.

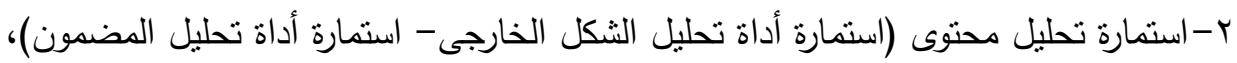
وقد قامت الدارسة بتصميم استمارة تحليل المحتوى تلبية لأهداف الدراسة. r-مقياس المسئولية البيئية: لقياس تأثثر المعرفة المقدمة فى تلك القضايا على تتمية المسؤلية البيئية لدى الجمهور من خلال إعداد مقياس المسئولية البيئية، وقد تم تحديد الهذف من لن

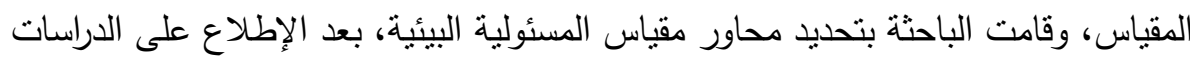

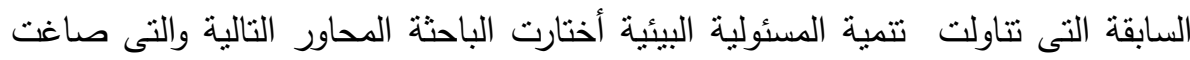

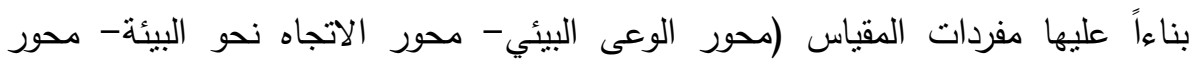
السلوك البيئى الايجابي- محور المشاركة واتخاذ القرار البيئى).

\section{مهناسهيم التراسما}

المواقع الإكترونية: هي منشور الكتروني دوري يحتوي على الاحداث الجارية سواء المرتبطة بموضوعات عامة اوبموضوعات ذات طبيعة خاصة، وينم قراءتها من خلال جهاز كومبيوتر وغالبا ما تكون مناحة عبر شبكة الانترنت، والمواقع الإلكترونية أحيانا ما تكون مرتبطة بصحيفة

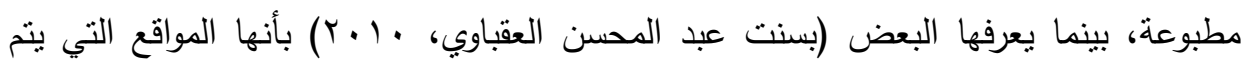

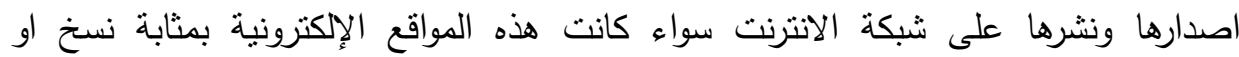
اصدارات الكترونية لصحف ورقية مطبوعة أو موجز لأهم محتويات النسخ الورقية، أو كجرائد ومجلات الكترونية ليست لها اصدارات عادية مطبوعة على الورق وتتضمن مزيجا من الرسائل الئل الاخبارية والقصص والمقالات والتعليقات والصور والخدمات المرجعية (السيد بخيت، ، ... بـم). القضايا البيئية: هى كل ما بطرح من الموضوعات، والمشكلات التى تحدث نتيجة اختلال توازن المنظومة البيئية وتتطلب مساهمة الجماهير فى حلها وتجنب حدوثها. 
المؤسسات الصحفية: إن المؤسسة الصحفية تهتم أساسا بإنتاج وتوزيع المعرفة فيشكل معلومات وأفكار، وثقافة، وذلك لتلبية الحاجات الإجتماعية التي تشكل في مجموعها حاجات

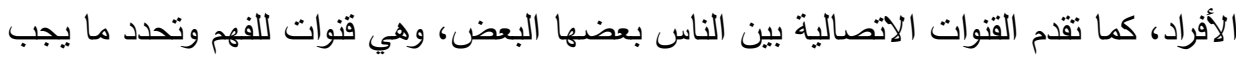

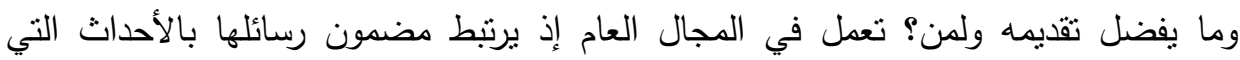

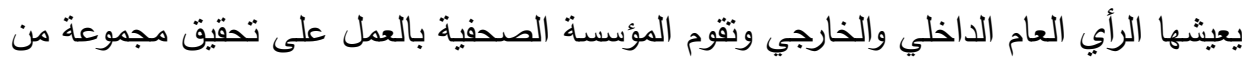
الوظائف المرتبطة بالمضمون والتحرير الصحفي والاعلان والتوزيع ويتصل الافراد عن طريقها

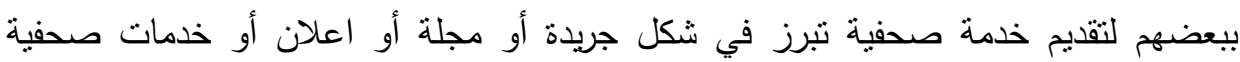
مختصة تحقق أهدافهم الخاصة والعامة فيظل ترتيب منظم للافراد والتقنيات المستخدمة (أحمد لئل زكريا أحمد، V. . . Y)، ولا تختلف المؤسسات الصحفية كثيراً عن أية مؤسسة أخرى باستثناء وجود إدارات مضافة إلى هيكلها التتظيمي لاداء الاعمال الصحفية والمهام المجاورة لها ذات الطبيعة الخاصة بهذه المهنة.

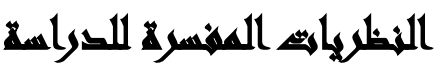

أولاً: نظرية تحليل الإطار الإعلامي: نتيح نظرية تحليل الإطار الإعلامى للباحث قياس المحتوى الضمني للرسائل الإعلامية التي تعكسها وسائل الإعلام وتقدم هذه النظرية تقسراً

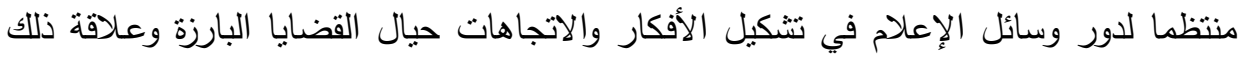

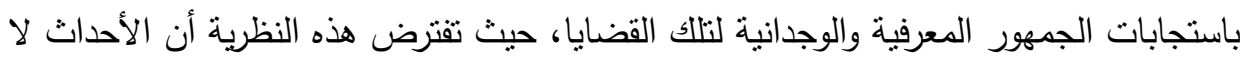
تتطوي في حد ذاتها على مغزى معين، وإنما تكتسب مغزاها من خلال وضعها في إطار يحددها

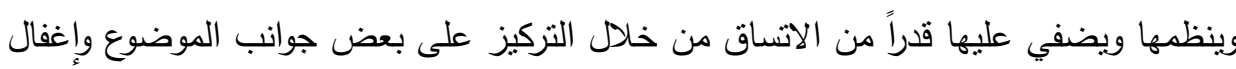

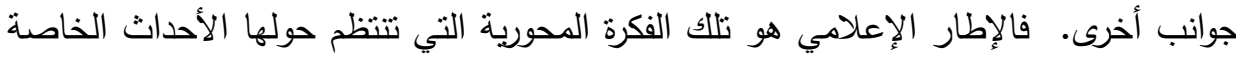
بقضية معينه والإطار الإعلامي لقضية ما يعني انتقاء متعدد لبعض جوانب الحدث أو القضية وجعلها أكثر بروزاً في النص الإعلامي واستخدام أسلوب وتحديد أسبابها وتقييم إبعادها وطرح حلول مقترحة بشأنها. ويحدد انتيمان أربع وظائف لتحليل الإطار الإعلامي هي: 
• تحديد المشكلة أوالقضية بدقة.

$$
\text { • • • • •تخيص أسباب المشكلة. }
$$

• اقتراح سبل العلاج، ويثير انتمان إلى إمكانية تتاول الأطر الإعلامية وفق مستوي أساسي.

المستوى الأول: تحديد مرجعية تساعد في عملية تمثيل المعلومات واسترجاعها من الذاكرة.

المستوى الثاني: يتعلق بوصف السمات التي تمثل محور الاهتمام في النص الاعلامي.

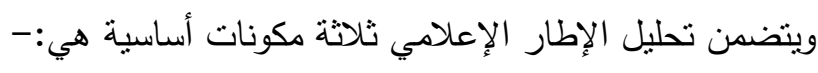$$
\text { • البناء التركيبي (الثكلي) للقصة الإخبارية. }
$$

• الفكرة المحورية.

هالاستتاجات الضمنية يجب التفريق بين نمطين أساسيين للأطر الاعلامية هما: الإطار

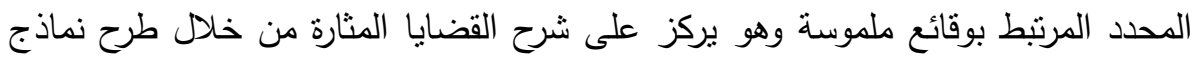

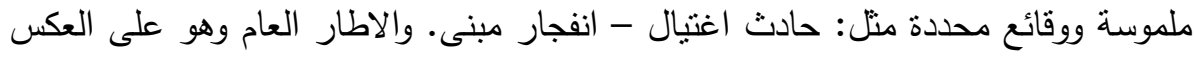

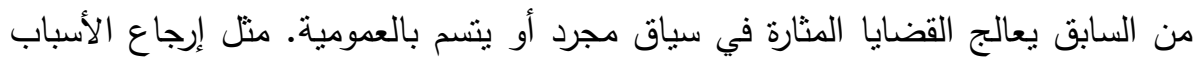

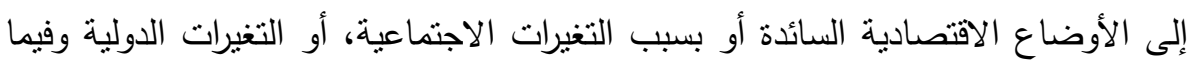
يتعلق بالقضايا البيئية يطرح الاسباب المؤدية لحدوثها. ثانياً: نظرية الاعتماد المتبادل: وتفسر نظرية الاعتماد فيما بتعلق بالاعتماد على وسائل الإعلام اعتماد الأفراد على وسائل الإعلام بشكل مباشر من أجل الحصول على المعلومات

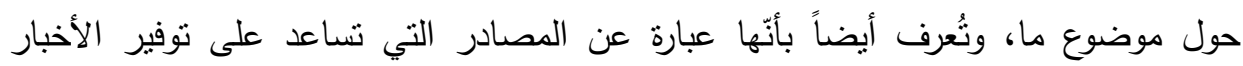
المُرنبطة بمجالٍ مُعيّن يهتمون بمتابعته، أو التي تتقل الأحداث المحلية، والدولية اليومية.

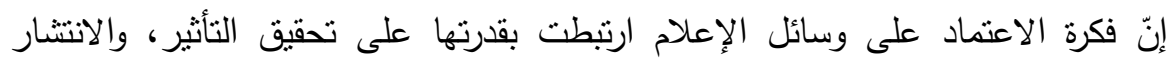

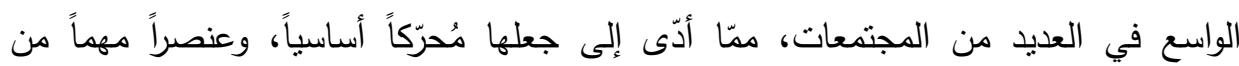

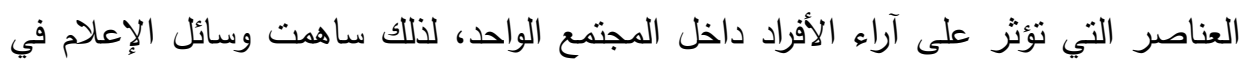

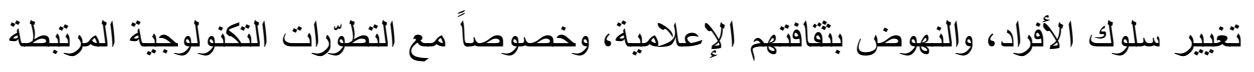

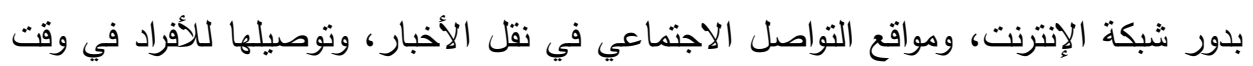


قصير جداً، ممّا ساهم في تعزيز فكرة الاعتماد على وسائل الإعلام في العديد من المجالات

وقد اوضحت الباحثة ساندرا روكينش، أنّ وسائل الإعلام تُصنّف كمصدر قوةٍ مؤثرة على الأفراد، والتي تساهم بتزويدهم بمجموعة من المعلومات حول مواضيع مختلفة، ووضع ديلفر

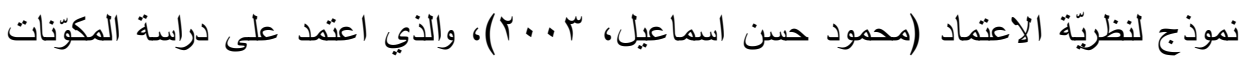
الرئيسّة للإعلام، وهي: وسيلة الإعلام، والمجتمع، والجمهور، وإنّ هذه المكونات تتكامل مع إعلى

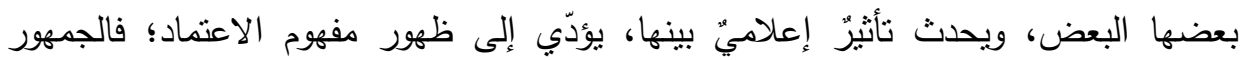
يَعتمدون على الأخبار المتداولة في المجتمع الذي يعيشون فيه، والمجتمع يَعتمد على وسائل لئل الإعلام في الحصول على هذه الأخبار، ممّا يؤدّي إلى انتشار الاعتماد على لئى وسائل الإعلام

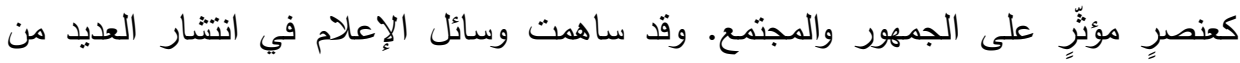

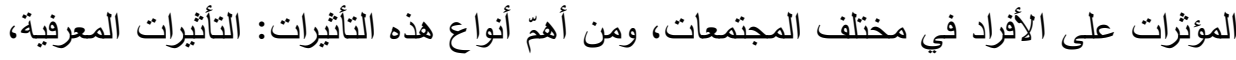

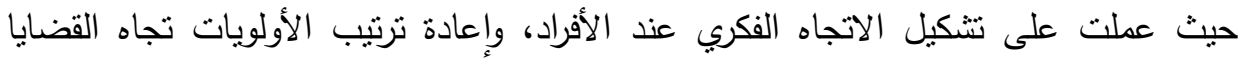

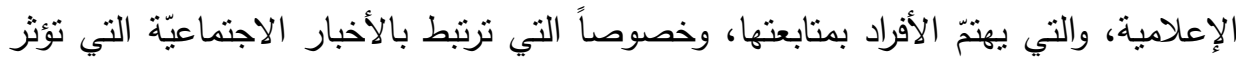

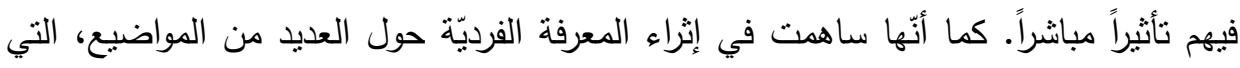

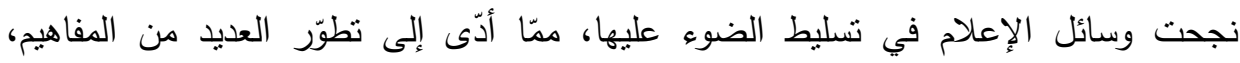

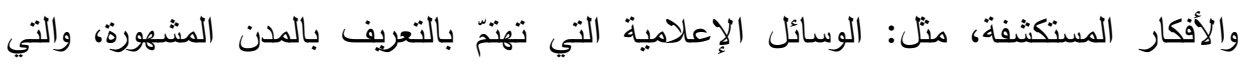
ساهمت في تعزيز دور السياحة بعد نعرّف الناس على طبيعة الحياة في هذه المدن. التأثيرات

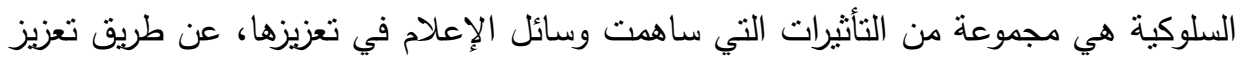

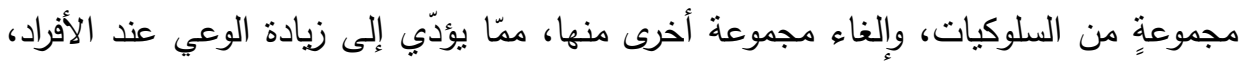

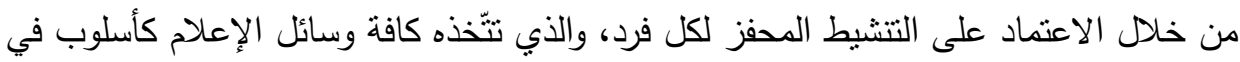

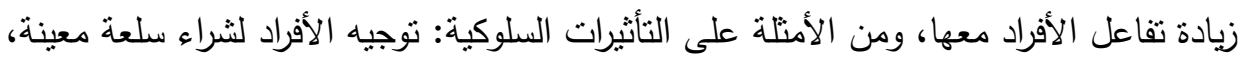

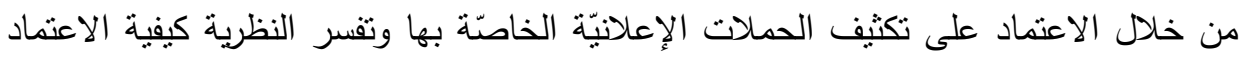
على وسائل الاعلام فى توجيه سلوكهم بشكل ايجابى تجاه قضايا البيئة. 


\section{إلجراعايت المهشه}

إعداد قائمة بالقضايا البيئية: (محلية- إقليمية- عالمية)، وذلك لتحديد القضايا والمشكلات

البيئية اللازمة لتتمية المسؤلية البيئية لجمهور المتلقين للصحف الالكترونية. أ- الاستعانة ببعض المراجع والدراسات والبحوث وثثقة الصلة بالقضايا والمشكلات البيئية التي

$$
\text { يجب تتاولها فى مواقع الصحف الإكترونية. }
$$

ب- نم عرض القائمة بصورتها الاولية على محكمين متخصصين.

ج- في ضوء ما أبداه السادة المحكمون، أصبحت القائمة في صورتها النهائية معدة لإستخدامها

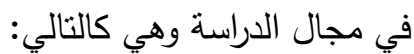

جدول (1): قائمة القضايا البيئية

\begin{tabular}{|c|c|}
\hline المشكلة الفرعية & المشكلة الرئيسية \\
\hline 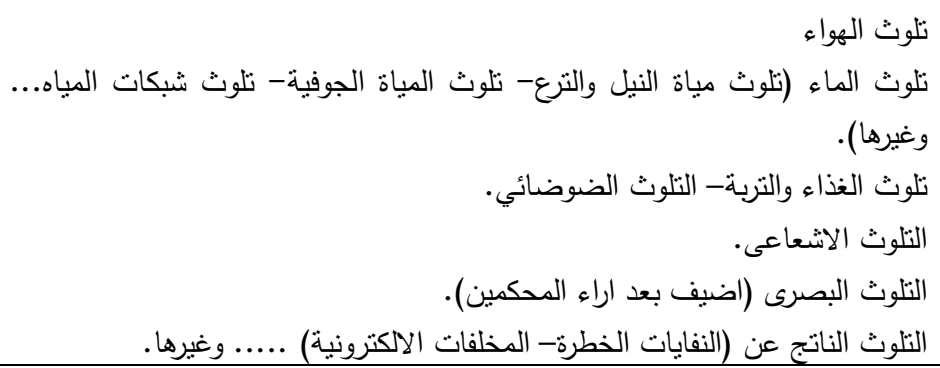 & 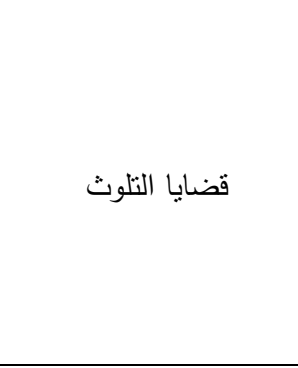 \\
\hline 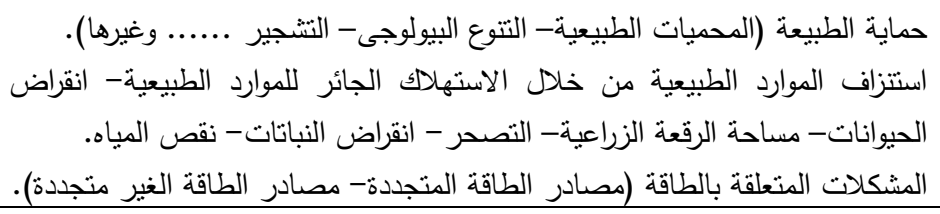 & قضايا متعلقة بالموارد \\
\hline الاحتباس الحراري- الاوزون- الأمطار الحامضية. & 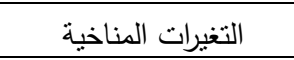 \\
\hline 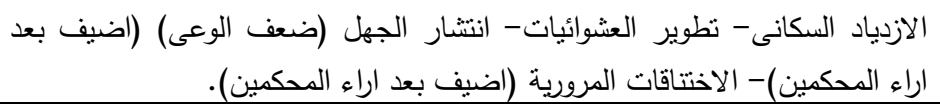 & 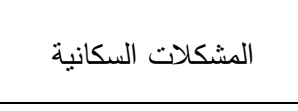 \\
\hline 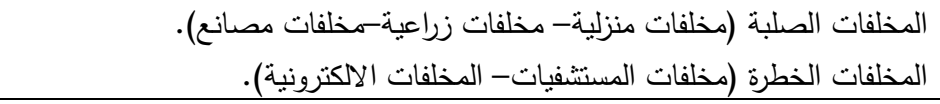 & 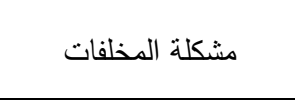 \\
\hline 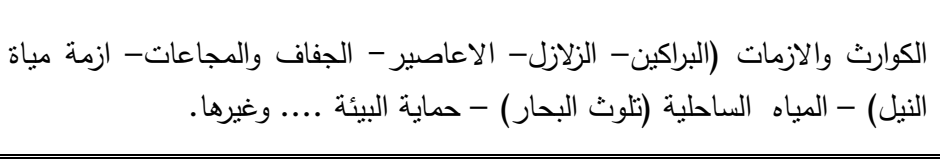 & 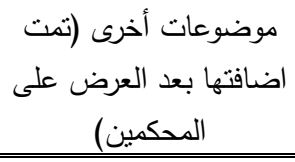 \\
\hline
\end{tabular}


استمارة تحليل محتوى القضايا البيئية التي قدمتها المواقع الاكترونية: بعد أن

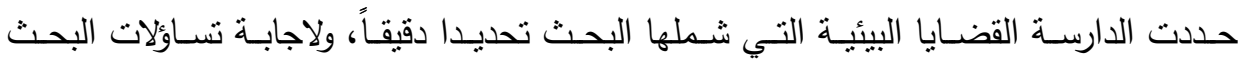
استخدت الدارسة أسلوب تحليل المحتوى، وذلك باختيار عينة المادة المقدمة موضع التحليل وتقسيمها وتحليلها كمياً وكيفياً.

تصميم استمارة النحليل وتحديد فئات التحليل، وتستخدم الفئات للاجابة عن سؤالين: ماذا قيل؟ وكيف قيل؟ وقد قسمت الدارسة الاستمارة إلى:

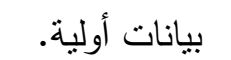

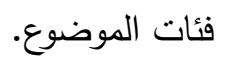

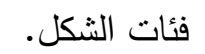

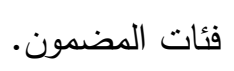

• البيانات الاولية: تضم هذه الفئة اسم الموقع الاككترونى موضوع النحليل وتاريخ اصداره ه فئات الموضوع: تضم الموضوعات البيئة الثالية: - النلوث: وقسم الى موضوعات فرعية كالتالي: تلوث الهواء - تلوث الماء (تلوث مياة النيل والتزع- تلوث المياة التوثة الجوفية- تلوث شبكات

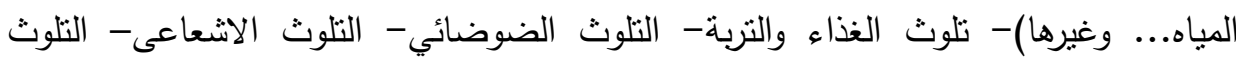

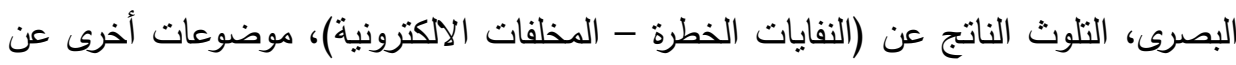
التلوث غير مدرجة بموضوعات التلوث السابقة. - قضايا متعلقة بالموارد الطبيعية: وقسم الى موضوعات فرعية كالتالي: حماية الطبيعة (المحميات الطبيعية- التتوع البيولوجي- التشجير ل.... وغيرها).

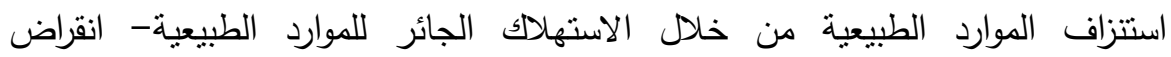

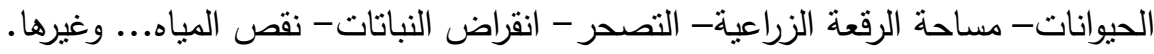
- المشكلات المتعلقة بالطاقة: (مصادر الطاقة المتجددة- مصادادر الطاقة الغير متجددة). - التغيرات المناخية: وقسمت الى مشكلات فرعية كالنالي: (الاحتباس الحراري- تخلخل طبقة

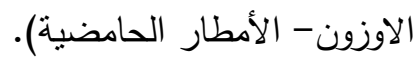


- الشكلات السكانية: وقسمت الى مشكلات فرعية كالتالي: الازدياد السكاني- العشوائيات-

$$
\text { انتشار الجهل (ضعف الوعى)- الاختناقات المرورية. }
$$

- مشكلة المخلفات: وقسمت الى موضوعات فرعية كالتالي: المخلفات الصلبة (مخلفات منزلية- مخلفات زراعية- مخلفات مصانع). المخلفات الخطرة (مخلفات المستثفيات-

$$
\text { المخلفات الالكترونية). }
$$

- مشكلات آخرى يمكن اضافتها لم ترد فى القضايا السابقة. ويتم تصنيف هذه القضايا والموضوعات والاستدلال عليها فى ضوء ما تتشره الجريدة عنها

$$
\text { من خلال عناوين رئيسية أو فرعية. }
$$$$
\text { فئئات الثكل: تضم هذه الفئة ما يلى: }
$$

- اساليب عرض القضايا البيئية: وتضم الاهتمام بالعرض من حيث: الموقع (مشار اليها

$$
\text { بالصفحة الرئيسية- الإكتفاء بعرضها فى الاقسام الداخلية). }
$$

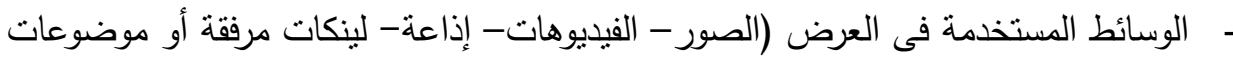
مشار إليها متعلقة بالموضوع- رسومات- الكلمات الفائقة (الهايير لينك)- كلمات نشطة...

- نمط المادة الاعلامية: (الخبر - المقال- التحقيق الصحفى (الملفات)- الحوار الصحفىالكاريكاتير - تقرير كسالة إلى الموقع أو صحافة المواطن). - - اللغة (فصحى- عامية- جمع بين العامية والفصحى). فئات المضمون: وتضم هذه الفئة ما يلى: - التصنيفات المكانية: ويقصد بها مكان الحدث البيئى وقسم إلى: عالمى: الموضوعات البيئية على مستوى العالم؛ إقليمي: الموضوعات البيئية على مستوى دول الاقليم؛ محلي: الموضوعات البيئية على مستوى الجمهورية. - الابعاد المتضمنة: ويقصد بها عناصر مضمون ما نشرته الجرائد عن القضايا البيئية وقسم

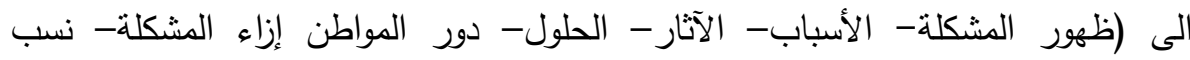


واحصائيات حول المشكلة- مؤتمرات وندوات- اتفاقية- ندوة- مؤتمر - خطة- قوانيندراسات- مطالبة مسئولين بالحل- مطالبة علماء بالحل).

- مصادر المعلومات: ما اعتمدت عليه فى نشر المعلومة وقسمت إلى (وكالات الانباءالمراجع العلمية- المسئولون- دراسات علمية- المتخصصون).

- كاتب الموضوع (الدحرر العلمي- الصحفي أو المراسل- صحفي متخصص- قارئ (من خلال صحافة مواطن- اراء الجمهور).

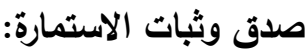

صدق الاستمارة: وتم اختبار صدق إستمارة تحليل المحتوى (استمارة تحليل الثكل + استمارة تحليل المضمون) بعرضها على السادة المحكمين والخبراء، وقد افاد المحكمون بمناسبة الإستمارة بعد تعديل بعض بنودها واضافة بعض البنود.

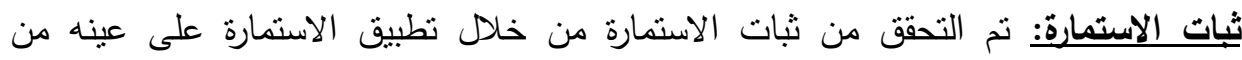

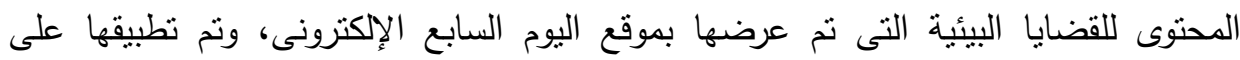

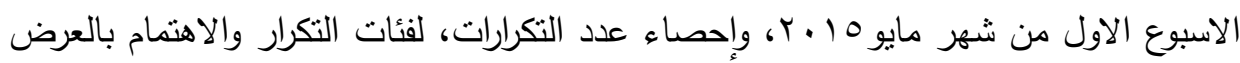

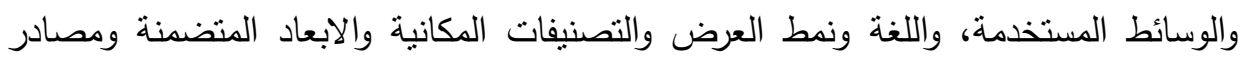

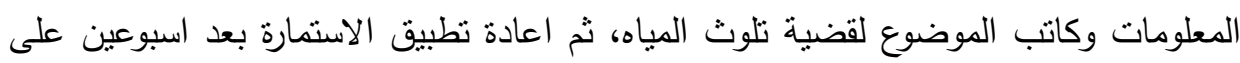
نفس العينة مرة أخرى وكانت النتائج كالتالى:

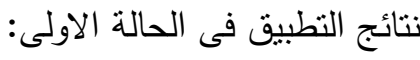


مجلة العلوم البيئية

معهد الدراسات والبحوث البيئية - جامعة عين شمس لبنه

جدول (ץ): استمارة تحليل محتوى من حيث الثكل

\begin{tabular}{|c|c|c|c|c|c|}
\hline$x_{0}=0.07$ & - & مث & \multirow{3}{*}{ H: } & \multirow{15}{*}{$\frac{\vec{z}}{\frac{\vec{E}}{\sigma}}$} & \multirow{15}{*}{$\frac{\ddot{E}}{\tilde{E}}$} \\
\hline "r.r. r. & + & intriad & & & \\
\hline "x, 1, & , & $x, 6=$ & & & \\
\hline \multirow[t]{4}{*}{ x、, } & , & sesist & \multirow{6}{*}{$\frac{5}{8}$} & & \\
\hline & - & 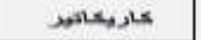 & & & \\
\hline & - & ts: & & & \\
\hline & - & Ma. & & & \\
\hline "x,, 1 & , & Satan & & & \\
\hline \multirow[t]{2}{*}{$x, \vee \vee, \wedge$} & $\checkmark$ & לبs & & & \\
\hline & - & 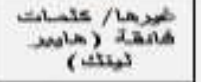 & \multirow{6}{*}{$E:$} & & \\
\hline$x, 4, \ldots$ & $=-1=$ & 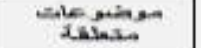 & & & \\
\hline \multirow[t]{2}{*}{$x, 7 x, \ldots$} & $\cdots / \mathrm{ra}$ & $\begin{array}{l}\text { MLAis } \\
\text { X.thits }\end{array}$ & & & \\
\hline & - & ريتهم & & & \\
\hline " & 011 & and & & & \\
\hline \multirow[t]{2}{*}{$x,+, 1$} & $=0,1$ & 3.9.9 & & & \\
\hline & $a$ & suat & S. & \multirow{5}{*}{$\frac{15}{r^{*}}$} & \multirow{5}{*}{$E ;$} \\
\hline \multirow[t]{3}{*}{$6,1,1$} & 冫 & 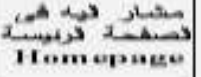 & 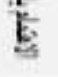 & & \\
\hline & - & & $E$ & & \\
\hline & 4 & & 5 & & \\
\hline and & 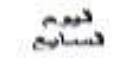 & \multicolumn{2}{|c|}{ ohtol } & & \\
\hline
\end{tabular}


محمود حسن اسماعيل وآخرون

جدول (ץ): استمارة تحليل محتوى من حيث المضمون

\begin{tabular}{|c|c|c|c|c|c|c|}
\hline$\%$ \%r,rp & $9 / r$ & بحرر متخصص & \multirow{4}{*}{$\begin{array}{l}\dddot{2} \\
\mathrm{~b} \\
\mathrm{E} \\
\mathrm{L}\end{array}$} & \multirow{15}{*}{ 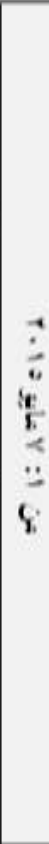 } & & \\
\hline$\% 11,11$ & $9 / 1$ & قاريا صحتة شواطلن & & & & \\
\hline \multirow[t]{2}{*}{$\% 74.7 \mathrm{~V}$} & $9 / 9$ & مراسل & & & & \\
\hline & - & تحرر طب & & & & \\
\hline \multirow[t]{2}{*}{$\% 11,11$} & $9 / 1$ & المتخصصون & \multirow{3}{*}{5} & & & \\
\hline & - & دراسات عنبة & & & & \\
\hline \multirow[t]{4}{*}{$\%$ YY,Y Y } & $9 / r$ & السمسونون & & & & \\
\hline & - & الثراجيع المنبية & \multirow[t]{2}{*}{$E$} & & & $E$ \\
\hline & - & وكالاتالانباء & & & & ti" \\
\hline & - & تاتشيات/ ثواتين & \multirow{10}{*}{$E$} & & & $t$ \\
\hline \multirow[t]{3}{*}{$\% r r, r r$} & $9 / r$ & مطائبة تسئونين & & & & : \\
\hline & - & خطة & & & & \\
\hline & - & براسيات & & & & \\
\hline \multirow[t]{2}{*}{$\% 11,11$} & $9 / 1$ & نسب وأحصائيات & & & & 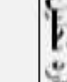 \\
\hline & - & 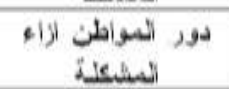 & & & & 1 \\
\hline$\% r r, r r$ & $9 / r$ & الحضول & & & \multirow{7}{*}{\multicolumn{2}{|c|}{$E$}} \\
\hline \%rr,rr & $9 / r$ & ا الעائ & & & & \\
\hline \multirow[t]{4}{*}{$\%: 4,4$} & $9 / 6$ & الأسباب & & & & \\
\hline & - & ظلهور السئكلدة & & $E$ & & \\
\hline & - & عائسم & \multirow{3}{*}{ E } & $\frac{T}{6}$ & & \\
\hline & - & اقلميس & & & & \\
\hline$\% 1 \ldots$ & 9 & منل & & & & \\
\hline
\end{tabular}

من جدول رقم r و ب يتضح أن مجموع فئات التحليل = To 
معهد الدراسات والبحوث البيئية - جامعة عين شمس لئن

نتائج تطبيق الاستمارة بعد مرور اسبوعين على اجراء التطبيق الاول:جلول(؛) : استمارة تحليل محتوى من حيث الثنكل

\begin{tabular}{|c|c|c|c|c|c|c|}
\hline$\% 00.07$ & $9 / 0$ & تهع يلين الاثثين & \multirow{3}{*}{$E$} & \multirow{14}{*}{ 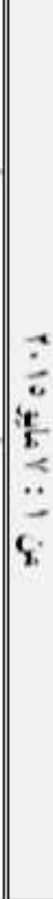 } & & \\
\hline \%r゙r.rr & $9 / \Gamma$ & |al & & & & \\
\hline$\%, 1,11$ & $9 / 1$ & عامية & & & & \\
\hline \multirow[t]{4}{*}{$\% 11,11$} & $9 / 1$ & تشّيد & \multirow{6}{*}{ है } & & & \\
\hline & & Solsus & & & & \\
\hline & & jو & & & & \\
\hline & - & مقال & & & & \\
\hline$\% 11,11$ & $9 / 1$ & تحمقيق & & & & \\
\hline$\% \vee Y, \wedge$ & $9 / \mathrm{V}$ & خير & & & & 8 \\
\hline & - & 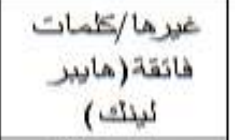 & \multirow{6}{*}{$E$} & & & E \\
\hline$\% q, \cdot 9$ & $00 / 2$ & 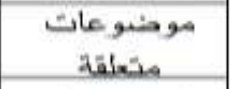 & & & & 6 \\
\hline \multirow[t]{2}{*}{$\% 79, .9$} & ০০/゙^ & كلمات نشطلد & & & & E: \\
\hline & - & 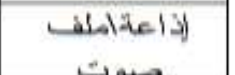 & & & & 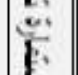 \\
\hline$\% 1,1$ & $00 / 1$ & فيدنو & & & & \\
\hline \multirow[t]{5}{*}{$\% Y 1, \wedge$} & م.0/1Y & الصنور & & & & \\
\hline & 9 & أقسام داخليحة & & \multirow{5}{*}{$\begin{array}{l}\text { L: } \\
c^{\prime} \\
\end{array}$} & \multirow{5}{*}{ E: } & \\
\hline & - & 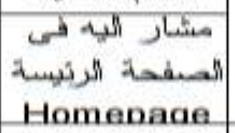 & بالمرض الامتم & & & \\
\hline & - & & المساحة & & & \\
\hline & 9 & & jالئil & & & \\
\hline 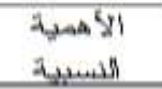 & الكيتيوت & \multicolumn{2}{|c|}{ أسم الموقت } & & & \\
\hline
\end{tabular}


محمود حسن اسماعيل وآخرون

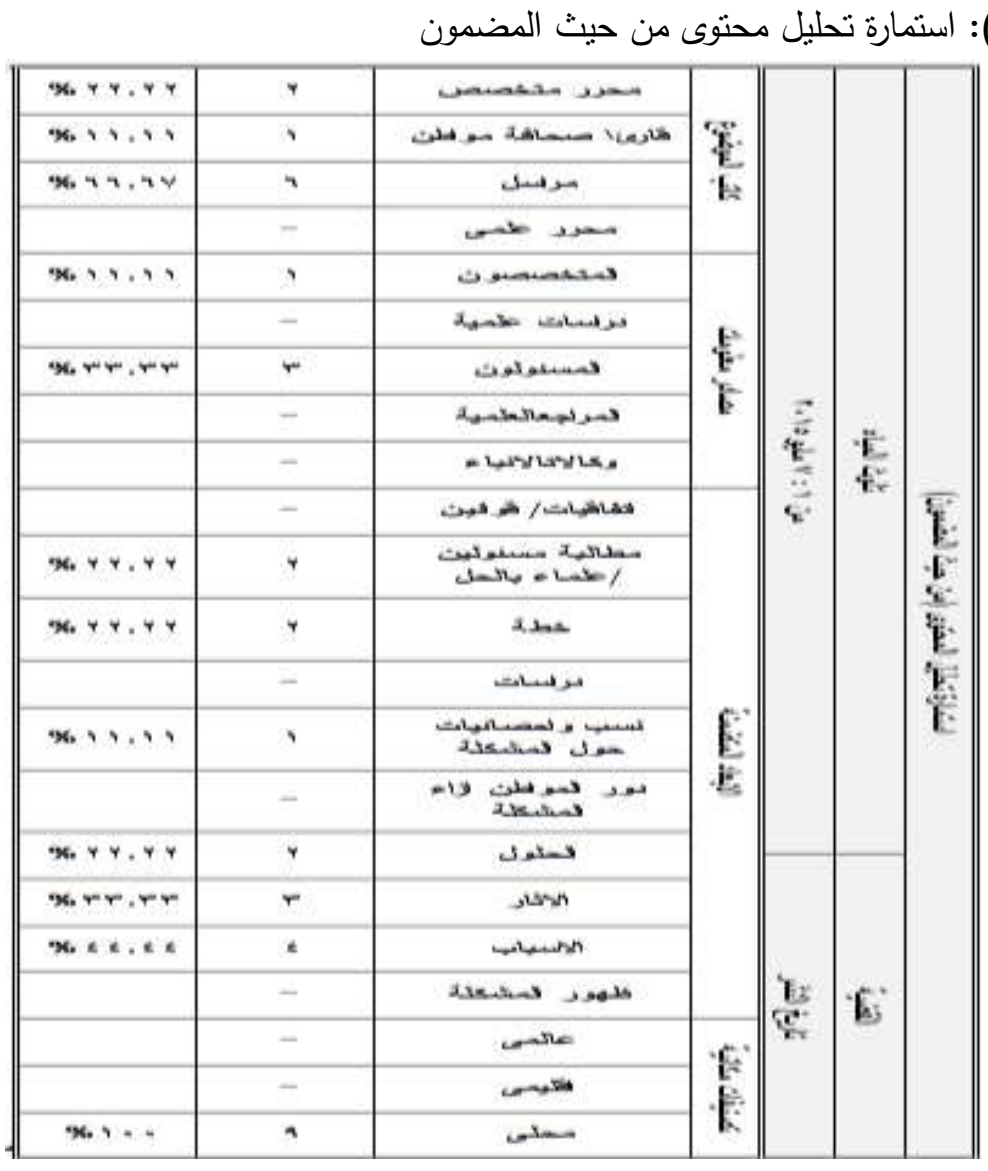

حساب ثبات الاستمارة بتطبيق معادلة هولستىى:

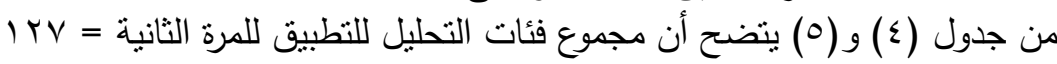

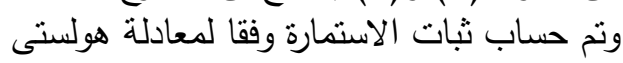

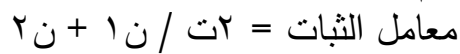

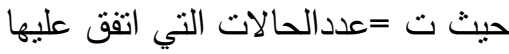
ن 1 = = عدد تكرار الفئات للمرة الاولى الفي ن و = = عدد تكرار الفئات للمرة الثانية

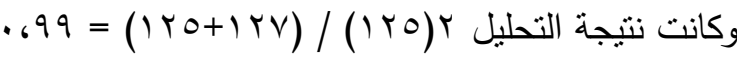

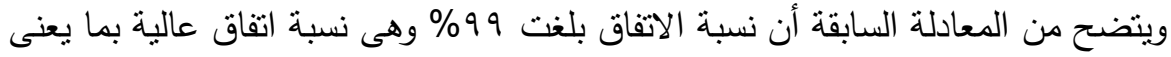

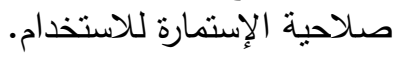




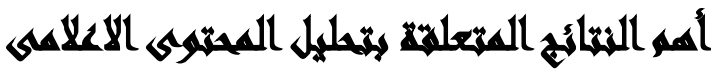

نتائج تحليل المحتوى بالنسبة لقضية التغيرات المناخية بالمواقع التثلاثة جائت كالتالي: جدول (†): استمارة تحليل محتوى من حيث الثكل

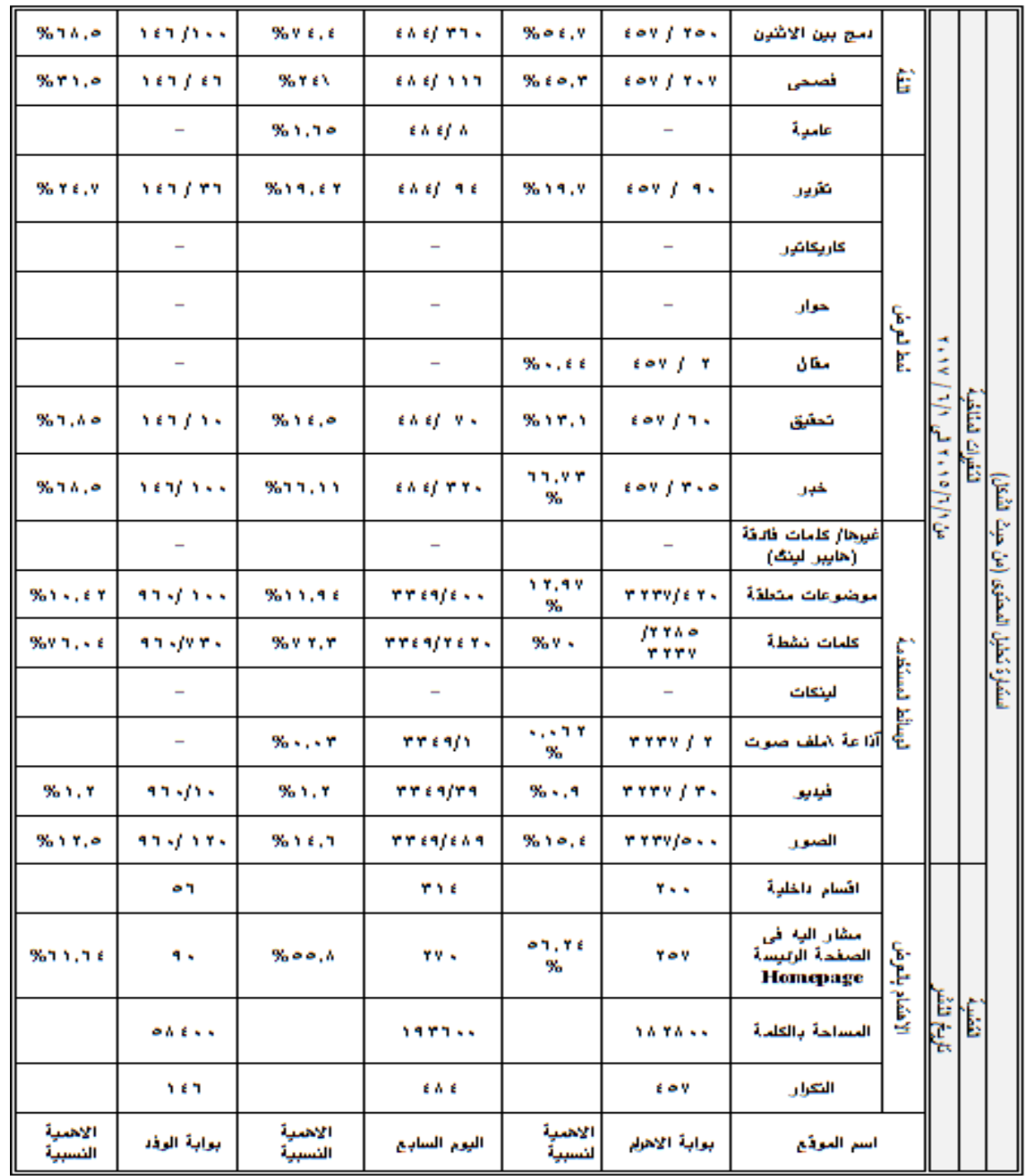


محمود حسن اسماعيل وآخرون

جدول (V): استمارة تحليل محتوى من حيث المضمون

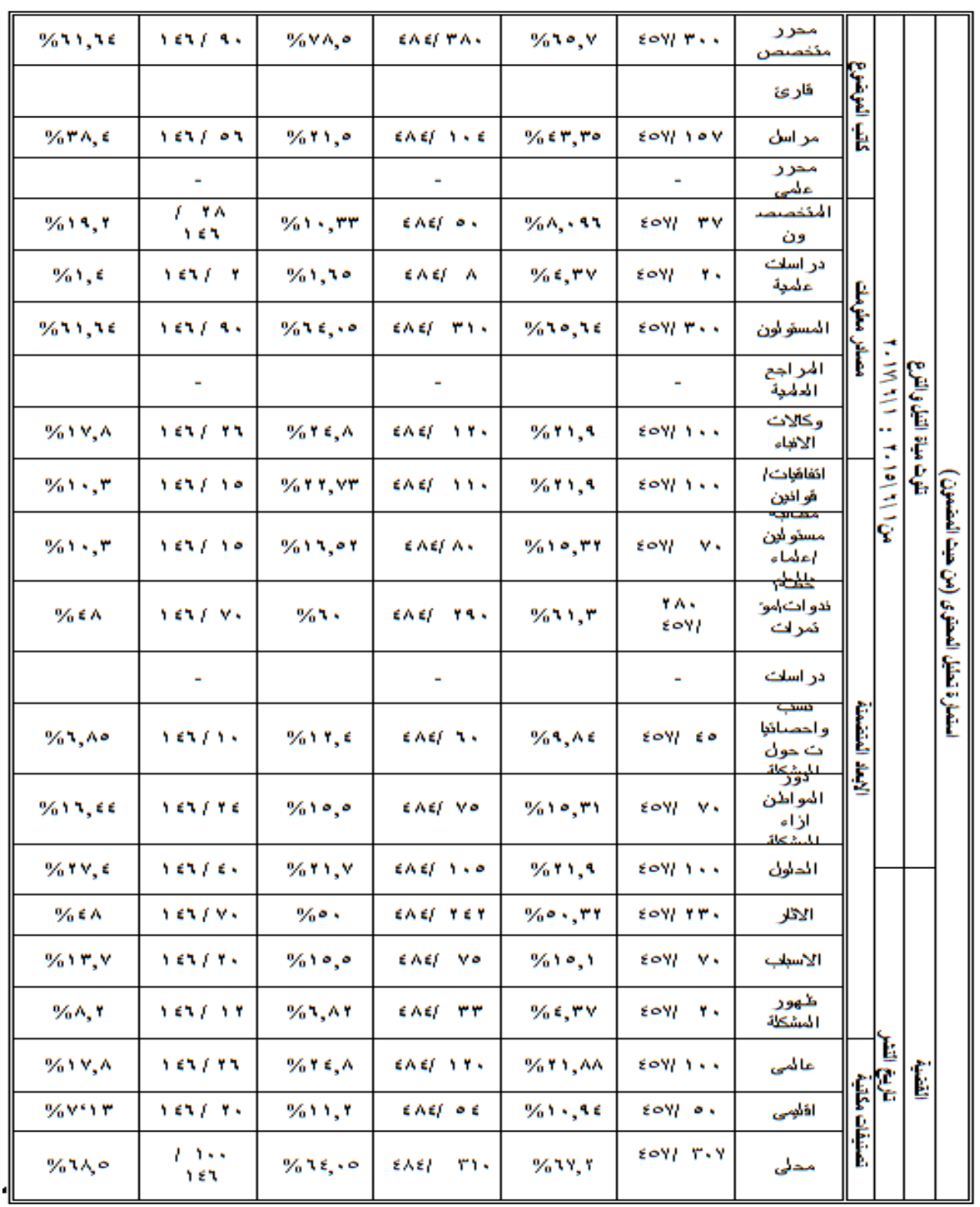




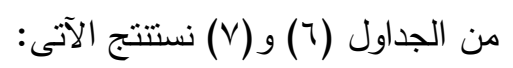

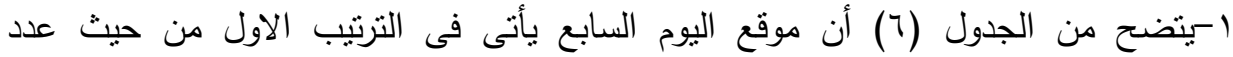

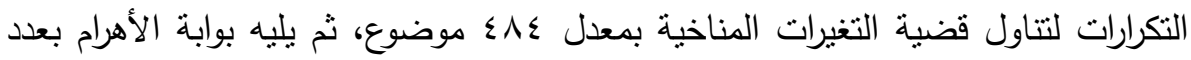

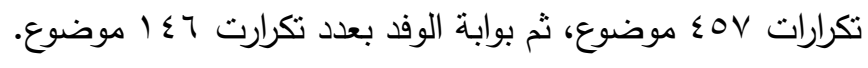

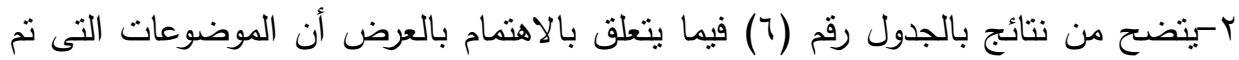

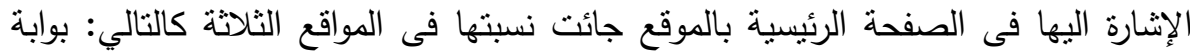

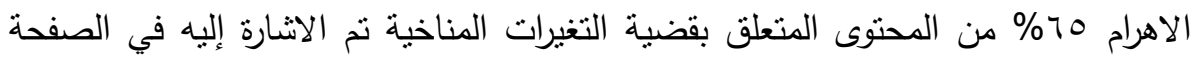
الرئيسية بالموقع V،00 \% من المحتوى المتعلق بقضية التغيرات المناخية تم الإثنارة اليه

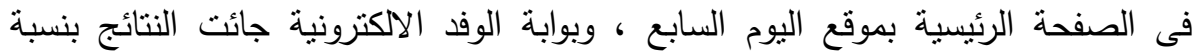

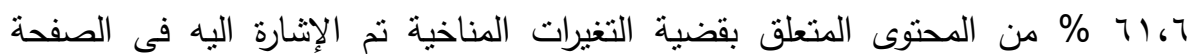

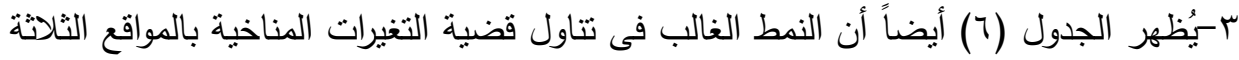

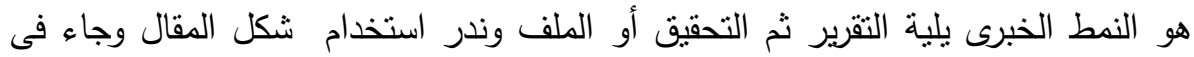
بوابة الاهرام الالكترونية فقط بنسبة ؟ ؛، ، \% وهى ضئيلة جدا، كذلك لم بستخدم نمط الحوار

الصحفى فى تناول قضية المنغيرات المناخية.

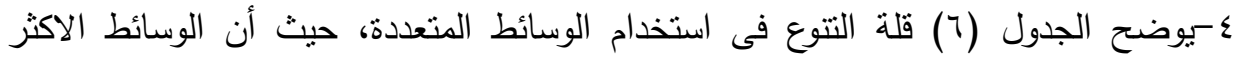

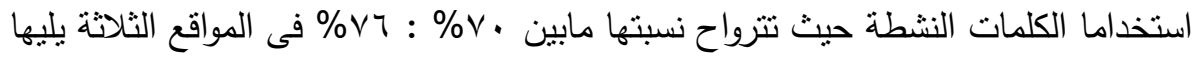
الصورة واستخدت بنسبة أعلى فى بوابة الاهرام ثم تلتها الموضوعات المتعلقة التى بشار

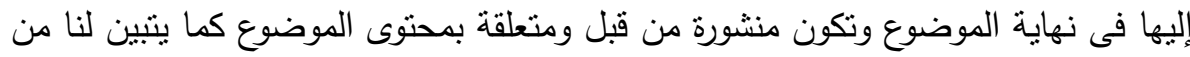

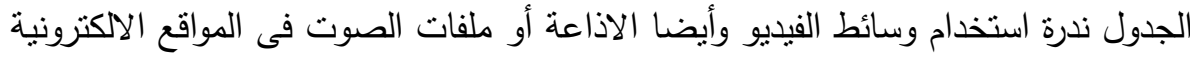

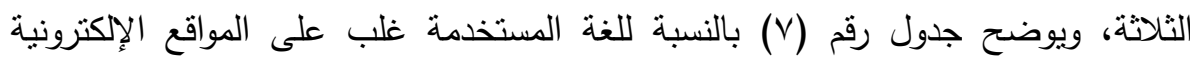

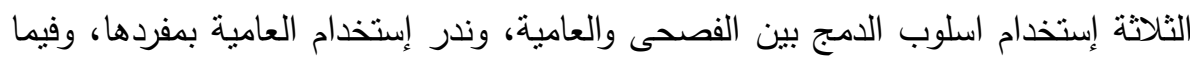

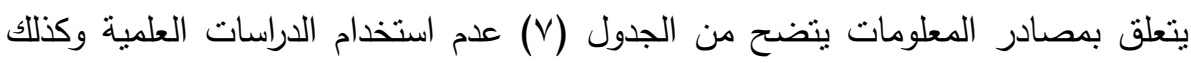
المراجع العلمية كمصدر للمعلومة البيئية المتعلقة بقضية التغيرات المناخية.

$$
\text { المجلد الحادي والأربعون، الجزء الثالث، مارس \1 ـ ب }
$$




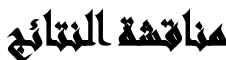

أثنارت النتائج المتعلقة بتحليل المحتوى الإعلامى للمواقع الإكترونية الثناثة (بوابة الاهرام

الإلكترونية- موقع اليوم السابع الإككتروني- بوابة الوفد الإلكترونية) إلى أن:

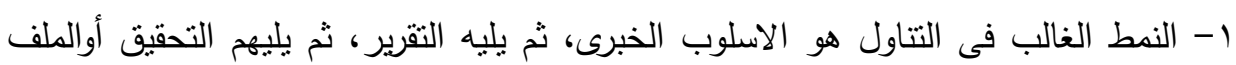

ولم يستخدم نمط الحوار الصحفى فى تتاول قضية التغيرات المناخية بالمواقع الثلاثة.

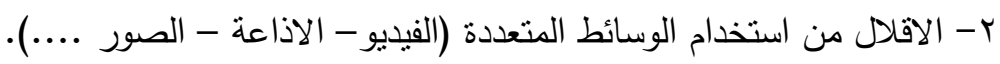

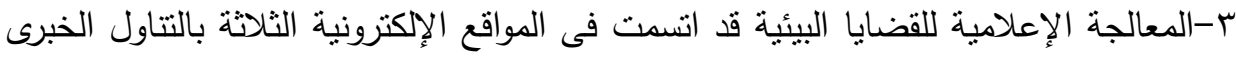
الموسمى، أى أن الحدث الآنى هو الذى يفرض نفسه ليتم تتاوله بحيث يتم عرض الإنه القضايل المثارة فى الوقت الراهن ويتم التركيز على عرض القضية البيئية وقت ظهور مشكلة متعلقة

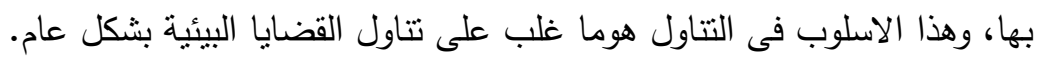
ع- قضية التغير المناخى تم تتاولها بصوره مكثفة خلال الثلاث سنوات التى تخللتهم فترة

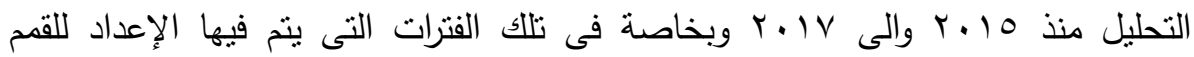

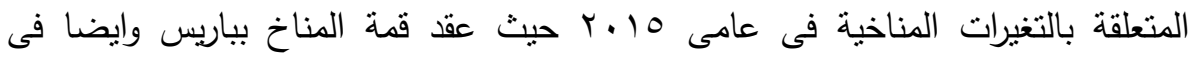

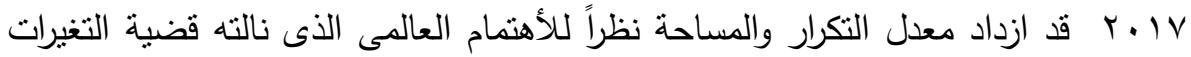

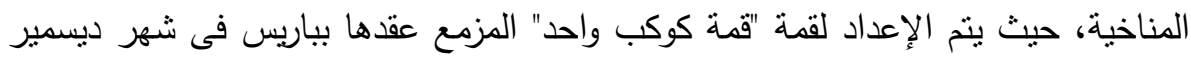
وبحضور وتمثيل كافة الدول الاعضاء بالامم المتحدة ومشاركة مصرية.

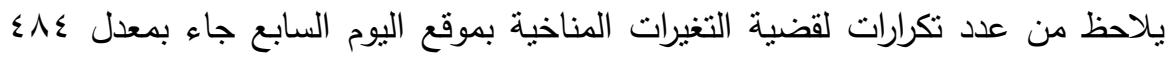

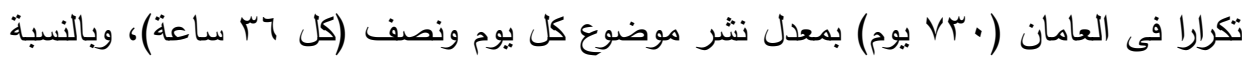

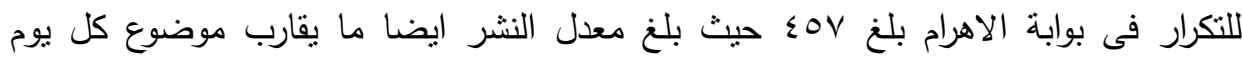

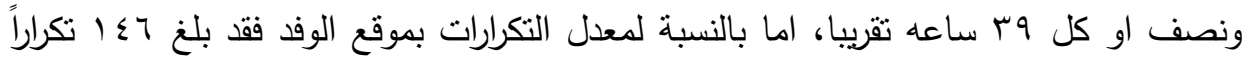

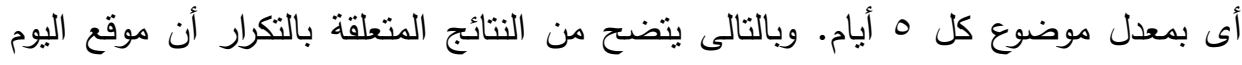
السابع كان معدل النشر فيه فى قضية النغيرات المناخية من حيث الفارق الزمنى بين الموضوعات هو الاقل فى الفارق الزمنى. 
توضح نتائج التحليل ايضا فيما يتعلق بقضية التغيرات المناخية أن ظهورها فى الصفحة

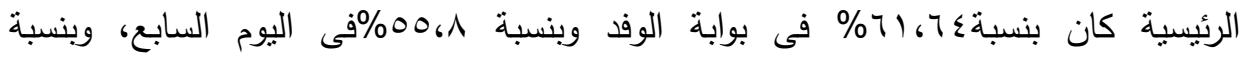

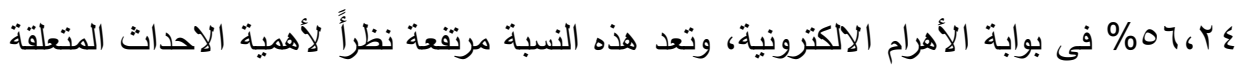

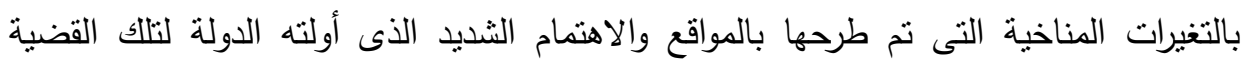

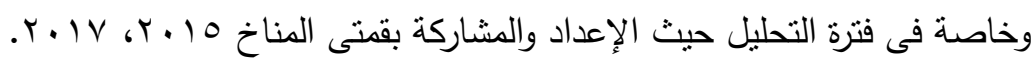
إعداد مقياس المسئولية البيئية: لقياس أثز التتاول للموضوعات على تتمية المسؤلية البيئية لدى الجمهور ويشمل على: (محور الوعى البيئى، محور الإتجاهات البيئية، محور السلوك البيئى الإِيجابى، محور المشاركة فى اتخاذ القرار البيئى).

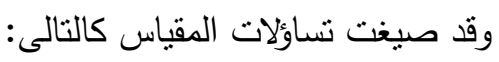
محور الوعى البيئي: ويهدف إلى قياس مدى وعي الجمهور بالقضايا والمشكلات البيئية وتم

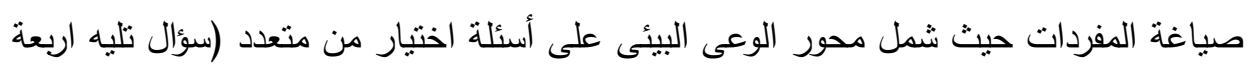

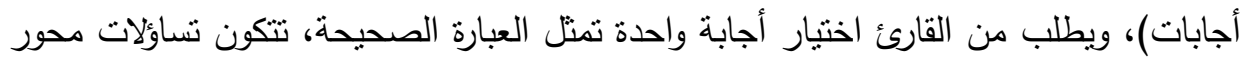

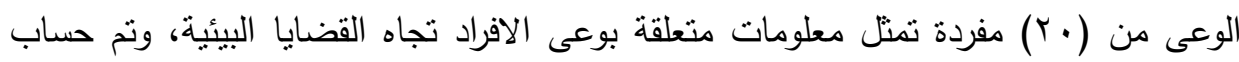

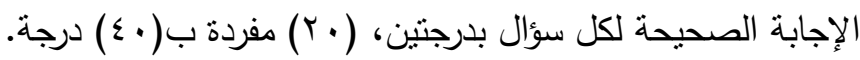

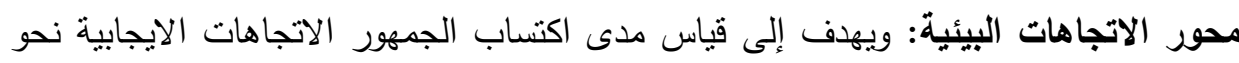

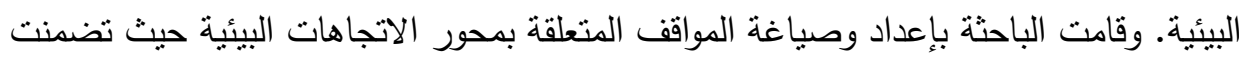

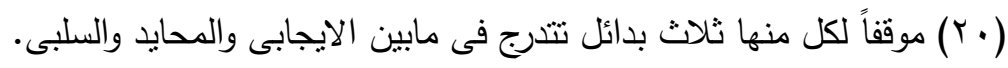
محور السلوك البيئى الايجابى: ويهدف إلى قياس مدى اكتساب سلوكاً بيئياً ايجابياً، وتم

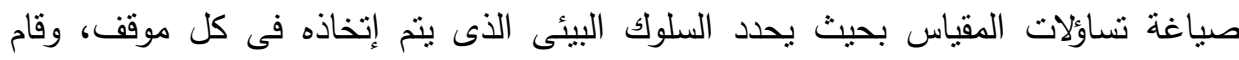
الباحثون بإعداد وصياغة مواقف محور السلوك البيئى الإيجابي حيث تضمن (10 (1) موقفاً لكل منها ثلاث بدائل تتدرج فى مابين الإيجابي والمحايد والسلبي. محور المشاركة فى القضايا البيئية واتخاذ القرار: ويهدف إلى فئ قياس مدى المشاركة فى اتخاذ قرار بيئي إيجابي، وقامت الباحثة بإعداد وصياغة مواقف المقياس حيث تضمن (10 (1) موقفاً لكل منها ثلاث بدائل تتدرج ما بين الإيجابى والمحايد والسلبى، تضمن التعليمات المتعلقة 
بالمحاور (الاتجاهات البيئية- السلوك البيئى الايجابى- المشاركة فى القضايا البيئية واتخاذ القرار) أن يختار ما بين البدائل الثلاثة ما يدل على مستوى المسئولية لديه. صدق المقياس: نم عرض المقياس على السادة المحكمين لنقويمة، فى ضوء آراء السادة الخبراء تم تعديل بعض البنود وأصبح المقياس فى صورته النهاية جاهزا للنطبيق. ولحساب ثبات المقياس نم تطبيقه على (• (1) من الصحفيين المتخصصين فى الإعلام البيئى.

\begin{tabular}{|c|c|c|c|c|}
\hline معامل الصدق & قيم الثبات & لارجة المقياسي العظمي & المقياس بنود & مكونات مقياس المسئولية البيئية \\
\hline$\% 99$ & $\% 9 \wedge, 1$ & $\varepsilon$ & $\cdot$ & محور الوعى البيئى \\
\hline$\% 99,1$ & $\% q \wedge, r$ & $\varepsilon$. & $r$. & محور الاتجاهات البيئية \\
\hline$\% 9 \wedge_{6} r$ & $\%$ \%४، & $r$. & 10 & محور السلوك البيئى الايجابى \\
\hline$\% 99.1$ & $9 \Lambda_{6}{ }^{2}$ & $r \cdot$ & 10 & محور المشاركة واتخاذ القرار البيئى \\
\hline$\% .91$ & $\% 9 \wedge$ & $1 \leqslant$. & . & مقياس المسئولية البيئية (ككل) \\
\hline
\end{tabular}

يتضح من الجدول رقم (^) أن قيمة ثبات مقياس المسئولية البيئية ككل بلغت (^9\%) وهى قيمة ثبات عالية، ودرجة الصدق بلغت (9^,9\%) مما يدل على صدق المقياس وصلاحيته للاستخدام.

الصورة النهائية لمقياس المسؤولية البيئية لدى الجمهور: بعد أن تحقق الباحثُن من صدق

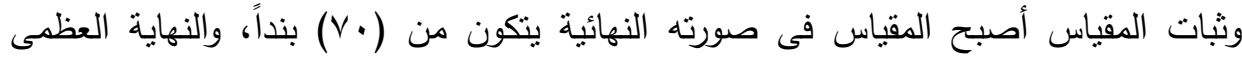
للمقياس (• ( ا ) درجة كما هو موضح في الجدول السابق. خطوات تطبيق مقياس المسئولية البيئية: تطبيق مقياس المسئولية البيئية (الوعي البيئي، الإتجاهات البيئية، السلوك البيئي الايجابي، المشاركة فى اتخاذ القرار). وقد تم تطبيق مقياس المسئولية على عينة من الثباب المتواجد بشكل دائم على شبكة الانترنت قوامها . 1 مفردة، وتم عمل صفحة فيس بوك مخصصة لغرض البحث وتم تطبيق المقياس القبلي على عينة الدراسة، ثم تم عرض المحتوى الاعلامي للقضايا البيئية المقدمة

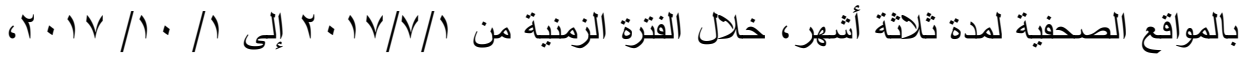

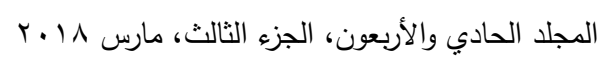


ثم تم تطبيق المقياس البعدى، ثم تم جمع البيانات وتحليلها ومعالجتها احصائياً تمهيداً للحصول على النتائج.

\section{نتائج تطبيق مقياس المسئولية البيئية:}

جدول(9): المقارنة بين القبلي والبعدي في مقياس المسئولية البيئية

\begin{tabular}{|c|c|c|c|c|c|c|c|c|c|}
\hline هجم الأثر & الدلالة & $\Xi$ & الحربح & التفرياري & منوسط & $\varepsilon$ & e & القُبلس & البعد \\
\hline \multirow{2}{*}{$\begin{array}{l}1 T, T Y \\
\text { Sيير }\end{array}$} & \multirow{2}{*}{ دالة } & \multirow{2}{*}{$41 .+11$} & \multirow{2}{*}{99} & \multirow{2}{*}{ i.v. } & \multirow{2}{*}{$11.0 \mathrm{r}}$. & $r \ldots r$ & r१,ร, & بعدي & \multirow{2}{*}{ الوعه } \\
\hline & & & & & & \&.rVq & IV.AT & كئلي & \\
\hline \multirow{2}{*}{$\begin{array}{l}\text { A.Or } \\
\text { SOيز }\end{array}$} & \multirow{2}{*}{ 11 } & \multirow{2}{*}{ EY,TVi } & \multirow{2}{*}{99} & \multirow{2}{*}{ r.ts. } & \multirow{2}{*}{1,01,} & r.VYA & YV.rA & بـدي & \multirow{2}{*}{ الاتجاه } \\
\hline & & & & & & 0.170 & $17 . \wedge \mathrm{V}$ & تاتيلي & \\
\hline \multirow{2}{*}{$\begin{array}{l}\text { A.01 } \\
\text { Sبير }\end{array}$} & \multirow{2}{*}{ دالة } & \multirow{2}{*}{ \&r.ro\} } & \multirow{2}{*}{99} & \multirow{2}{*}{ r.1.99 } & \multirow{2}{*}{ Ir.tA. } & $1.01 \mathrm{~T}$ & ro,ol & sister & \multirow{2}{*}{ السلوكيثت } \\
\hline & & & & & & $r . \varepsilon 11$ & Ir.rY & تثله & \\
\hline \multirow{2}{*}{$\begin{array}{l}\text { 9. } 5 \text {. } \\
\text { ins }\end{array}$} & \multirow{2}{*}{ دالكة } & \multirow{2}{*}{$\varepsilon T . Y \leqslant V$} & \multirow{2}{*}{94} & \multirow{2}{*}{ Y.VEz } & \multirow{2}{*}{ Ir.74. } & $1.0 . Y$ & Yo, Yor & بعدي & \multirow{2}{*}{ المشاركة } \\
\hline & & & & & & T.IVT & IY.OV & كيلب & \\
\hline \multirow{2}{*}{$\begin{array}{l}11.51 \\
\text { كبير }\end{array}$} & \multirow{2}{*}{ دالة } & \multirow{2}{*}{07.711} & \multirow{2}{*}{99} & \multirow{2}{*}{ A.r. } & \multirow{2}{*}{$\varepsilon v . .0}$. & A.ArV & l. v,,$\Delta$ & span & \multirow{2}{*}{ المكالمه } \\
\hline & & & & & & 10,810 & 7,0, & ماثلب & \\
\hline
\end{tabular}

يتضح من الجدول السابق أن جميع الابعاد ومجموعها الكلي كانت دالة عند ه.., • مما يدل علي انه توجد فروق دالة بين القياسيين القبلي والبعدي لصالح القياس البعدي (المتوسط الأعلي) وقد كان حجم الاثر كبيرا لانه اكبر من ^,، • مما يدل علي أن تأثثر المتغير المستقل

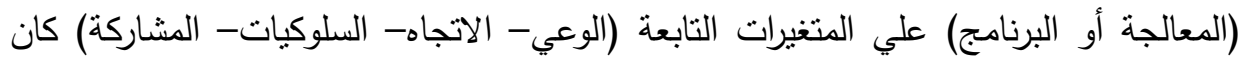
تأثيراً كبيراً. والرسم البياني التالي يوضح الجئ ذلك: 
محمود حسن اسماعيل وآخرون

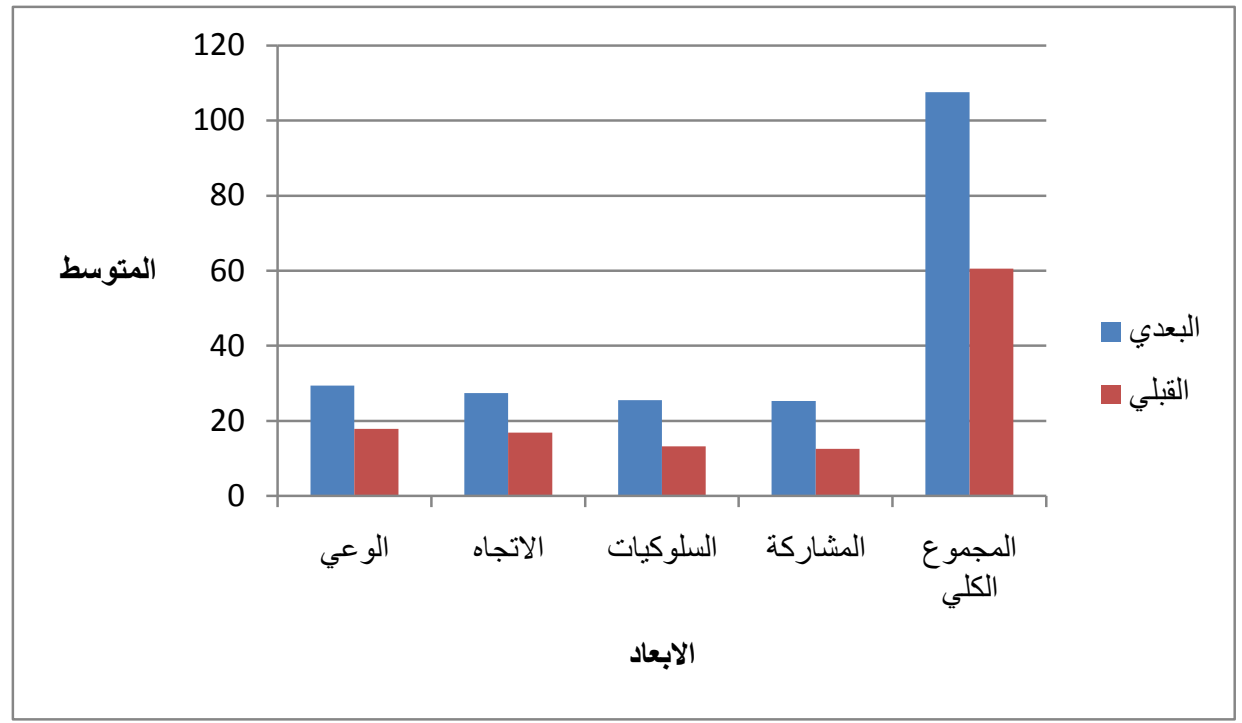

أثنارت نتائج تطبيق مقياس المسئولية البيئية الى وجود فرق دال إحصائياً بين متوسط درجات مجموعة الدراسة قبل التطبيق وبعده لصالح التطبيق البعدي، بما يدل على نتمية المسئولية

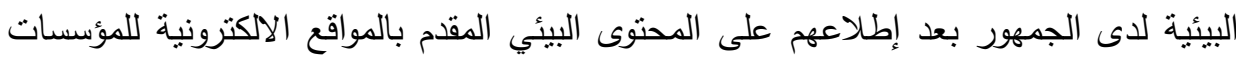

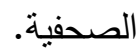

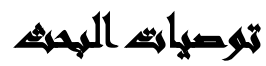

فى ضوء ما توصلت إليه الدراسة من نتائج يمكن تقديم التوصيات الآتية:

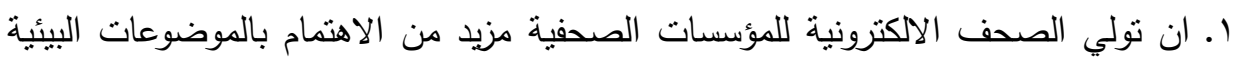

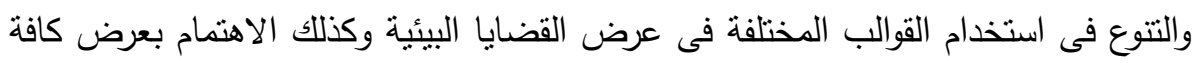
جوانب القضية البيئة من اسباب حدوثها والاثر الناجم عنها وطرح الحلول والحلول البديلة ودور الجمهور تجاه تللك القضايا وكيفية المشاركة فى حلها من خلال سلوك بيئى ايجابى اوالمشاركة فى اتخاذ القرار البيئي. r. تدريب الصحفيين بالجوانب المختلفة للقضايا البيئية وايضا استخدام القوالب والاساليب الصحفية المختلفة لعرض القضايا بطرق أكثر تأثثراً وبشكل جاذب للقارئ. 
r. تخصيص قسم ثابت لقضايا البيئة بالبوابة أو الموقع الالكترونى يشرف عليه صحفي متخصص فى القضايا البيئية للنشر بشكل منتظم.

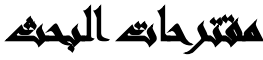

تقترح الدراسة توجيه القائمين على اصدار المواقع الالكترونية للمؤسسات الصحفية بتخصيص مسئول فى مجال التربية البيئية لعرض القضايا والمشكلات المجتمعية الخاصة بالبيئة، يشرف عليها لجنة ثقافة البيئة بالمجلس الاعلى للتقافة.

\section{sall}

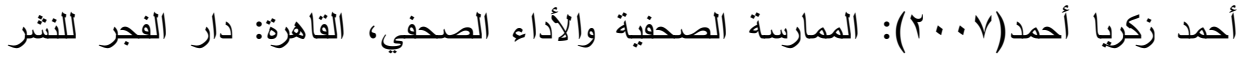
والتوزيع

أشرف فهي خوخة(1) (1)): الإخراج الصحفي والصحافة الإلكترونية، الإسكندرية: دار المعرفة

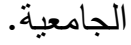

أمل محمد خطاب(· ( • م) م) تكنولوجيا الاتصال الحديثة ودورها في تطوير الأداء الصحفي،

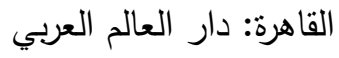

السيد بخيت( . . . rم): الصحافة والإنترنت، القاهرة: العربي للنشر والتوزيع طا داري

السيد نج(r Y (Y): النشر الإلكترونى، نقنية جديدة نحو أفاق جديدة، الهيئة المصرية العامة للكتاب

انتصار موسى(r . . r م): تصميم واخراج الصحف والمجلات والإعلانات الإلكترونية، طا،

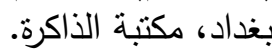

بسنت عبد المحسن العقباوى( • ( • بم): الصحافة الإلكترونية وبنيتها على شبكة الإنترنت، جدة، مجلة خوارزم العلمية

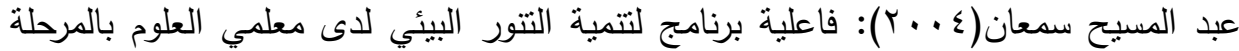

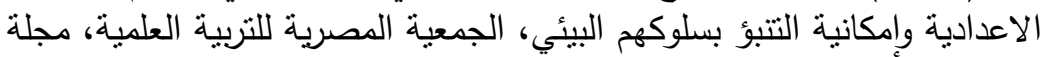

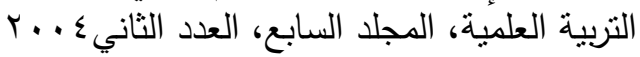

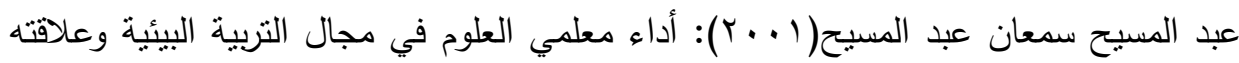
بالوعي البيئي لدى تلاميذهم بمرحلة التعليم الأساسي، مجلة التربية العلمية التراية التئية

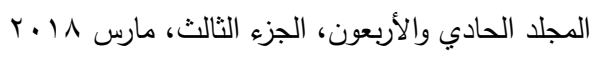


ماجدة عبدالفتاح الهلباوى(0 1 ب): الاعلام الدولى والالكترونى، طا، الاسكندرية، دار التعليم

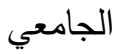

محب محمود كامل الرافعي(997 (1): التتور البيئي لدى طالبات كليات التربية للبنات بالمملكة

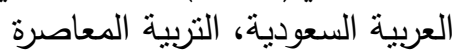

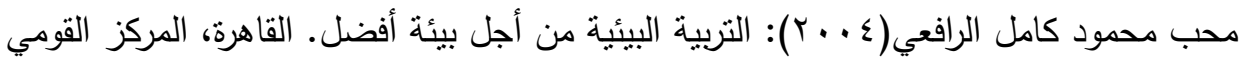
للبحوث التزبوية والتنمية

محمد عبد الفتاح القصاص(ب99 (99): الإنسان وقضايا البيئية، معهد البحوث والدراسات العربية،

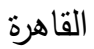

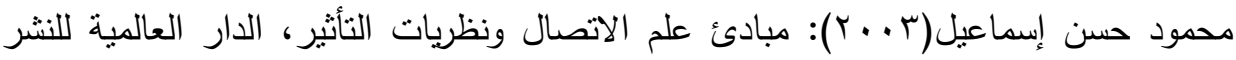
والتوزيع.

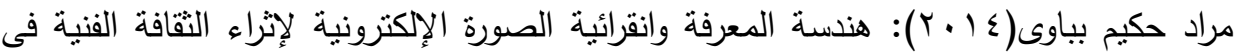
التربية الفنية. القاهرة، طاله، مكتبة عالم الكتب.

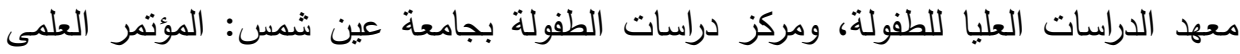

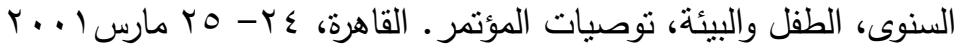

مؤتمر الأمم المتحدة المعنى بالبيئة والتتمية: وثثية جدول أعمال القرن (Y) (Y) الخاص بمؤتمر

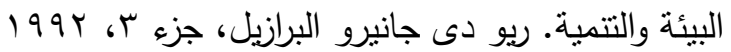

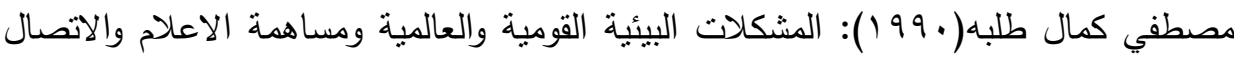
في مواجهتها، مجلة النيل، الهيئة العامة للاستعلامات العدد · ــ القاهرة.

أبو بكر محمد الهوش(1) (ب): شبكة الإنترنت وخدمات المعلومات، القاهرة: دار السحاب

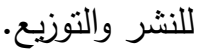

Bryner, Gary, C. Bryner (1993, 1995): Blue skies, Greenpolitics: The clean air act of 1990 and its implementation. Washington, D.C: CQ press,C 1995, 1993.

Diaz-Ortiz, Claire (Aug., 30 ${ }^{\text {th }}, 2011$ ): Twitter for Good: Change the World One Tweet at a Time, USA: Jossey-Bass; $1^{\text {st }}$ ed.

Hawker, Mark, D. (Aug., 25 ${ }^{\text {th }}, 2010$ ): Developer's Guide to Social Programming: Building Social Context Using Face book, Google Friend Connect, and the Twitter API, Canada: Addison-Wesley Professional; $1^{\text {st }}$ ed.

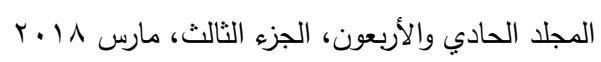




\section{مجلة العلوم البيئية \\ معهد الدراسات والبحوث البيئة - جامعة عين شس الثس}

Hawker, Mark. D. (Aug., 25 ${ }^{\text {th }}$, 2010): Developer's Guide to Social Programming: Building Social Context Using Face book, Google Friend Connect, and the Twitter API, Canada: Addison-Wesley Professional; $1^{\text {st }}$ ed.

Hewitt, Hugh (Jan., 14 $\left.4^{\text {th }}, 2005\right)$ : Blog: Understanding the Information Reformation That's Changing Your World, USA: Thomas Nelson, Inc.; $1^{\text {st }}$ ed.

Jenkins, Henry (Sept., $\left.1^{\text {st }}, 2008\right)$ ): Convergence Culture: Where Old and New Media Collide, USA: NYU Press; Revised edition.

Roth, Charles (1992): Environmental Literacy; Its Roots Evolution and Direction in the 1990's Education Development Center. Newton, Massachusetts, P.1.

Syme, Geoffrey \& others (2002): the limits of Environmental Responsibility Astor Water Case Study, Environmental \& behavior no. Vo.134(6) pp.863 - 847.

UNESCO / UNEP (1985): Environmental Education Module for inservice training of Teachers and Supervisors for Primary School, Environmental Education Series , No.6, P. 13.

UNESCO / UNEP (1989): Environmental Literacy for all, Vol. 19, No. 2, P.1.

University of Wisconsin, College of Natural Resources (2004): NABE Conference.

Vogel, David (1947, 1995): Trading up consumer and environmental regulation in a global economy, Cambridge, Mass: Harvard university press 1995 .

Lister, Martin; Dovey, Jon; Giddings, Seth; Grant, Iain \& Kelly, Kieran (Jan., 29 ${ }^{\text {th }}$, 2009): New Media: A Critical Introduction, USA/UK Europe: Routledge; $2^{\text {nd }}$ ed.

Zhenmin, Xiahua (2002): Survey and Evaluation on Residents Environmental Journal of Environment \& Pollution > Geneva: Vol. 17. Iss. 4 p.310.

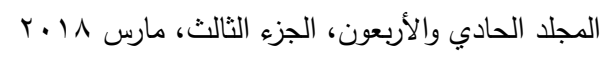




\title{
MEDIA TREATMENT OF ENVIRONMENTAL ISSUES \\ ON SOME WEBSITES FOR PRESS INSTITUTION AND \\ ITS IMPACT ON DEVELOPMENT OF \\ ENVIRONMENTAL RESPONSIBILITY TO THE \\ PUBLIC
}

Ismael, M. H. ${ }^{(1)}$; Bebaoy, M. H. ${ }^{(2)}$ and Arsanious, Gehan, A.

1) Institute of Higher Education for Children 2) National Center for Educational Research and Development

\begin{abstract}
The study has included media presentation of environmental issues in some of the websites of the press institutions and their impact on the development of environmental responsibility in the public. The study seeks to recognize the media processors for environmental issues in some of the websites of the press institutions. The study includes a sample of the following websites (Al-Ahram online site- Alyoum alsabee online site- Alwafd online site).

The researchers have prepared a set of research tools with verification of its validity, stability and validity of application; which is a tool to determine content information on environmental issues provided to the press institutions websites (Al-Ahram online site- Alyoum alsabee online site- Alwafd online site). As well as a questionnaire to solicit the views and concerns of the public in which the websites produce with regard to environmental issues. And also prepared a measure of environmental responsibility to measure the impact of the media treatment of environmental issues by some web sites of press institutions on developing responsibility of audience. It has been determined axes of the plugs according to what has been found with previous studies. And the application of management content analysis of the websites of the
\end{abstract}

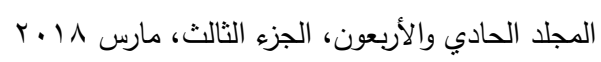


press institutions in the seeking, And Administration application form polled the audience on sample of the online sites public on the internet itself Containing 450 individuals each, Has also been The application of a measure of environmental responsibility on sample of young people who are permanently on the internet Containing 100 individuals each.

The results of application of the environmental liability measure indicate that there is a statistically significant difference between the average of the study group before and after the application for favor of the application of after. The study recommends that the websites of press institutions should give more importance for environmental issues; also use different templates in the view of environmental issues as well as view all aspects of the environmental issue of the reasons for their occurrence and the impact caused by it and the solutions and alternative solutions and the role of the public towards those issues and how to participate in the solution through the enviro-positive behavior or to participate in decision-making environmental

Keywords: Environmental issues; the websites; the press institutions; Environmental responsibility. 